\title{
Spectroscopic and Electronic Structure Studies of Intermediate X in Ribonucleotide Reductase R2 and Two Variants: A Description of the Fe $\mathrm{F}^{\mathrm{IV}}-\mathrm{Oxo}$ Bond in the Fe'll-O-Fe'lv Dimer
}

\author{
Nataša Mití ${ }^{\dagger}, \S, \|$, Michael D. Clay ${ }^{\dagger}, \|$, Lana Saleh ${ }^{\ddagger}$, J. Martin Bollinger Jr $\ddagger$, and Edward I. \\ Solomon ${ }^{\dagger}$ \\ $\dagger$ Department of Chemistry, Stanford University, Stanford, California 94305 \\ $\$$ Department of Biochemistry and Molecular Biology, The Pennsylvania State University, University Park, \\ Pennsylvania 16802
}

\section{Abstract}

Spectroscopic and electronic structure studies of the class I Escherichia coli ribonucleotide reductase (RNR) intermediate $\mathrm{X}$ and three computationally-derived model complexes are presented, compared and evaluated to determine the electronic and geometric structure of the $\mathrm{Fe}^{\mathrm{III}}-\mathrm{Fe}^{\mathrm{IV}}$ active site of intermediate X. Rapid freeze-quench (RFQ) EPR, absorption and MCD were used to trap intermediate $\mathrm{X}$ in $\mathrm{R} 2$ wild-type (WT) and two variants, W48A and Y122F/Y356F. RFQ-EPR spin quantitation was used to determine the relative contributions of intermediate $\mathrm{X}$ and radicals present, while RFQ-MCD was used to specifically probe the $\mathrm{Fe} \mathrm{e}^{\mathrm{III}} / \mathrm{Fe}^{\mathrm{IV}}$ active site, which displayed three $\mathrm{Fe}^{\mathrm{IV}}$ d-d transitions between $16700-22600 \mathrm{~cm}^{-1}$, two $\mathrm{Fe}^{\mathrm{IV}}$ d-d spin-flip transitions between 23 $500-24300 \mathrm{~cm}^{-1}$ and five oxo to $\mathrm{Fe}^{\mathrm{IV}}$ and $\mathrm{Fe}^{\mathrm{III}}$ charge transfer (CT) transitions between $25000-$ $32000 \mathrm{~cm}^{-1}$. The $\mathrm{Fe}^{\mathrm{IV}} \mathrm{d}-\mathrm{d}$ transitions were perturbed in the two variants, confirming that all three $\mathrm{d}-\mathrm{d}$ transitions derive from the $\mathrm{d}-\pi$ manifold. Furthermore, the $\mathrm{Fe}^{\mathrm{IV}} \mathrm{d}-\pi$ splittings in the WT are too large to correlate with a bis- $\mu$-oxo structure. The assignment of the $\mathrm{Fe}^{\mathrm{IV}} \mathrm{d}$-d transitions in WT intermediate $\mathrm{X}$ best correlates with a bridged $\mu$-oxo/ $\mu$-hydroxo $\left[\mathrm{Fe}^{\mathrm{III}}(\mu-\mathrm{O})(\mu-\mathrm{OH}) \mathrm{Fe}^{\mathrm{IV}}\right]$ structure. The $\mu$-oxo/ $\mu$-hydroxo core structure provides an important $\sigma / \pi$ superexchange pathway, which is not present in the bis- $\mu$-oxo structure, to promote facile electron transfer from Y122 to the remote $\mathrm{Fe}^{\mathrm{IV}}$ through the bent oxo bridge, thereby generating the tyrosyl radical for catalysis.

\section{Introduction}

Binuclear non-heme iron-containing active sites are found in a large number of enzymes that perform highly specific oxidation reactions involving binding and activation of dioxygen. ${ }^{1-3}$ This class of enzymes includes hemerythrin (reversible $\mathrm{O}_{2}$ binding), ${ }^{4,5}$ soluble methane monooxygenase (sMMO, hydroxylation of methane), ${ }^{6,7}$ stearoyl acyl carrier protein $\Delta^{9}$ desaturase $\left(\Delta^{9} \mathrm{D} \text {, fatty acid desaturation }\right)^{8-10}$ and the $\mathrm{R} 2$ subunit of class I ribonucleotide reductase (RNR, generation of stable tyrosyl radical). ${ }^{11-14}$ Current research centers on understanding the structural and electronic features of the binuclear iron clusters that govern the diverse reactivity of these enzymes with $\mathrm{O}_{2}$. Crystal structures exist for many proteins in this class in oxidized and/or reduced forms. ${ }^{15-17}$ Each protein contains carboxylate and histidine ligands that coordinate the binuclear iron core responsible for the reductive activation

Correspondence to: J. Martin Bollinger, Jr, jmb21@psu . edu.

$\S$ Current address: Department of Chemistry, University of Queensland, St. Lucia, QLD 4072, Australia.

"Both authors contributed equally to this study. 
of $\mathrm{O}_{2}$, generating similar peroxo-diferric and high-valent iron-oxo intermediates that have been observed and characterized in some of these enzymes. ${ }^{18-23}$

Ribonucleotide reductase catalyzes the rate-limiting step in DNA biosynthesis in all organisms, the reduction of ribonucleotides to their corresponding deoxyribonucleotides. ${ }^{13,14}$ The R1 subunit of the Escherichia coli RNR holoenzyme R1・R 2 complex contains the ribonucleotide catalytic active site, whereas the R2 subunit contains the binuclear $\mathrm{Fe}^{\mathrm{II}}$ active site, which (along with an exogenous electron) reductively activates $\mathrm{O}_{2}$ resulting in one-electron oxidation of an endogeneous Y122 residue to form a tyrosyl radical and an oxo-bridged diferric cluster, as shown in Scheme 1. The generation of this stable Y122 - makes R2 active to initiate a longrange $(\sim 35 \AA$ ) proton coupled electron transfer (PCET), between the two subunits, to the catalytic active site in the R1 subunit. ${ }^{24}$ This leads to the formation of a thiyl radical on C439 of R1 and ultimately nucleotide reduction. 25

Crystal structures of both reduced and oxidized R2-WT and several variants combined with spectroscopy have greatly contributed towards the understanding of the binuclear non-heme iron active site. 12,15 The active site structures of both diferrous and diferric R2-WT are shown in Figure 1. In the fully reduced form of R2-WT (see Figure 1A), the two irons centers are separated by a distance of $3.9 \AA$, with the Fe1 being 4C and Fe 2 5C, as supported by MCD spectroscopy. 26,27 The two carboxylate residues, Glu115 and Glu238 bridge the two Fe centers in a $\mu-1,3$ fashion and the rest of coordination is completed by His 118 and monodentate Asp84 on Fe1, and bidentate Glu204 and His 241 on the Fe2 center. Tyr122, which gets oxidized to the stable radical, is $\sim 5 \AA$ away from Fe1 and is $\mathrm{H}$-bonded to Asp84. ${ }^{28-30}$ The major change during the conversion of the binuclear iron cluster from diferrous to diferric form involves a significant reorganization of two carboxylates, Glu238 and Asp84. In oxidized R2-WT (see Figure 1B), both Fe centers become $6 \mathrm{C}$ with an Fe-Fe distance of $3.3 \AA$. There is one bridging $\mu$-1,3 carboxylate from Glu115 and a single $\mu$-oxo bridge (from $\left.\mathrm{O}_{2}\right)^{31}$ between the two Fe ${ }^{\mathrm{III}}$ centers. Fe1 is coordinated to His 118, bidentate Asp84, and a terminal solvent molecule (water or hydroxide), whereas Fe2 coordination is completed by His241, monodentate Glu204 and Glu238, and a terminal solvent molecule.

Major efforts have been directed toward defining the structural and electronic properties of high valent iron-oxo intermediates, specifically in sMMO and R2.1,6,32-34 sMMO catalyzes the two electron oxidation of methane to methanol and both intermediates $\mathrm{P}$ or $\mathrm{H}_{\text {peroxo }}$ (peroxo $\mathrm{Fe}^{\mathrm{III}} 2$ complex) and $\mathrm{Q}\left(\mathrm{Fe}^{\mathrm{IV}}{ }_{2}\right.$ species) have been trapped and kinetically characterized in sMMO. ${ }^{20,21}$ The methane-hydroxylating intermediate, $\mathrm{Q}$, characterized by Mössbauer and EXAFS spectroscopies, exhibits an $S=0$ diamagnetic ground state and is thought to contain a bis- $\mu$-oxo core structure with two antiferromagnetically-coupled $\mathrm{Fe}^{\mathrm{IV}}$ ions at an $\mathrm{Fe}-\mathrm{Fe}$ distance of $2.46 \AA .35$ For R2, there is evidence for the formation of a cis- $\mu$-1,2-peroxo $\mathrm{Fe}^{\mathrm{III}}{ }_{2}$ intermediate similar to $\mathrm{P}$ in D84E variants of the $E$. coli protein and the WT protein from mouse. 23,36 During the assembly of the $\mathrm{R} 2$ binuclear iron in the presence of $\mathrm{O}_{2}$, an intermediate $\mathrm{X}$ (an oxo-bridged $\mathrm{Fe}^{\mathrm{III}} \mathrm{Fe}^{\mathrm{IV}}$ species) has been identified kinetically and spectroscopically (by stopped-flow, EPR, ENDOR, EXAFS, and RFQ-MCD). 19,28,37-41 The latter decays to give the stable Y122 and oxo-bridged diferric cluster. Mössbauer spectroscopy was consistent with $\mathrm{X}$ containing two inequivalent iron sites, a high-spin $\mathrm{Fe}^{\mathrm{III}}(S=5 / 2)$ antiferromagnetically coupled to a high-spin Fe $\mathrm{Fe}^{\mathrm{IV}}(S=2)$ yielding a resultant $S_{\text {tot }}=1 / 2$ spin system. ${ }^{19,28}$ This magnetic coupling between the two iron atoms is also evident from a nearly isotropic $S=1 / 2$ EPR signal at $g=2$. The short distance between the two iron atoms in intermediate $X(2.5 \AA)$ determined from EXAFS ${ }^{37}$ results in combination with ${ }^{17} \mathrm{O}$ and ${ }^{1,2} \mathrm{H}$ ENDOR spectroscopy 39,40 indicated the presence of at least one $\mu$-oxo bridge, with the second oxygen atom being coordinated to the $\mathrm{Fe}^{\mathrm{III}}$ site as a terminal water or hydroxide. The presence of two additional bridging ligands (carboxylates) in either a $\mu-1,1$ or $\mu-1,3$ bridging mode has also been inferred. The spectroscopic data on both intermediate X and Q are of high interest as both 
have distinctly short Fe-Fe distances with the spectra implicating a different number of bridging oxo ligands. Alternatively, a number of computational analyses, $33,42-52$ including the most recent study by Noodleman and coworkers, ${ }^{53}$ have concluded that $\mathrm{X}$ contains a bis- $\mu$-oxo core structure, similar to the proposed structure of intermediate Q in sMMO.

Thus, the structure of $\mathrm{X}$ remains to be determined and the geometric and electronic description of $\mathrm{X}$ is required to understand the mechanism of tyrosyl radical formation in RNR. Recently, we developed a rapid-freeze-quench magnetic circular dichroism technique (RFQ-MCD) to probe electronic and structural properties of intermediate $X$, utilizing a double variant of RNR $(\mathrm{Y} 122 \mathrm{~F} / \mathrm{Y} 356 \mathrm{~F})$, which allowed for the generation of up to 1.4 equivalents of $\mathrm{X} .{ }^{38}$ These MCD data permitted direct detection of the high-spin $\mathrm{Fe}^{\mathrm{IV}}$ spin-allowed and forbidden ligand field transitions.

In the present study RFQ-MCD is used in combination with low temperature (LT) absorption, VTVH MCD, and EPR spectroscopies to obtain a detailed experimental description of the ligand-metal bonding in the catalytically active $\mathrm{Fe}^{\mathrm{III}}-\mathrm{Fe}^{\mathrm{IV}}$ binuclear site of $\mathrm{X}$ in the $\mathrm{R} 2$ subunit of RNR in WT and two variants, a double variant $\mathrm{Y} 122 \mathrm{~F} / \mathrm{Y} 356 \mathrm{~F}$ and a single variant W48A. In R2-WT, $\mathrm{X}$ forms in a second order reaction between the biferrous active-site and $\mathrm{O}_{2}$ with a rate constant of $k_{\text {form }}=2.1 \pm 0.2 \times 10^{5} \mathrm{~mol}^{-1} \mathrm{~s}^{-1}$ and decays with a rate constant of $k_{\text {decay }}=$ $1.0 \pm 0.2 \mathrm{~s}^{-1}$ at $5^{\circ} \mathrm{C}$, whereas in $\mathrm{R} 2 \mathrm{Y} 122 \mathrm{~F} / \mathrm{Y} 356 \mathrm{~F}, \mathrm{X}$ had a formation rate constant $k_{\text {form }}=5$ $\pm 1 \times 10^{4} \mathrm{~mol}^{-1} \mathrm{~s}^{-1}$ and $k_{\text {decay }}=0.3 \pm 0.1 \mathrm{~s}^{-1}$ at $11^{\circ} \mathrm{C}$. ${ }^{54,55}$ Thus, the replacement of easily oxidizable Y122 and Y356 residues with phenylalanines leads to high yields of pure X (up to 1.4 eq.) with increased lifetime. The decay of X in R2-Y122F/Y356F variant generates a tyrosyl radical from one of the nearby tyrosine residues in the protein, as it cannot oxidize F122. The crucial role of W48 in the ET process of R2 has been recently investigated. ${ }^{54-57}$ In both W48F and $\mathrm{W} 48 \mathrm{~A}$ variants of $\mathrm{R} 2$, a diradical intermediate species containing both intermediate $\mathrm{X}$ and $\mathrm{Y} 122 \bullet(\mathrm{X}-\mathrm{Y} 122 \bullet)$ is formed from a preceding $\mathrm{Fe}_{2} \mathrm{O}_{2}$ complex with a $k_{\text {form }}=7.5 \pm 2.5 \mathrm{~s}^{-1}$ and with a $k_{\text {decay }}=0.18 \pm 0.04 \mathrm{~s}^{-1} .54-57$ The kinetic parameters and the Y122• production stoichiometry for the R2-W48A variant are very similar to those reported earlier for R2-W48F. 55 These experimental data presented here are complemented by DFT, TD-DFT, $\triangle \mathrm{SCF}$ and Slater transition state calculations to examine the ligand field transition energies of the $\mathrm{Fe}^{\mathrm{IV}}$ site to correlate to three possible model core structures for X: mono- $\mu$-oxo, $\mu$-oxo/ $\mu$-hydroxo and bis- $\mu$-oxo (vide infra). This study correlates the experimental spectroscopic data with DFT calculations to elucidate the fundamental features of the $\mathrm{Fe}^{\mathrm{IV}}$-oxo bond in $\mathrm{X}$, understand the effects of the geometric perturbations on the $\mathrm{Fe}^{\mathrm{III}}-\mathrm{O}-\mathrm{Fe}^{\mathrm{IV}}$ unit and to evaluate its geometric and electronic structural contributions to the formation of Y122.

\section{Experimental Section}

All commercial reagents of highest grade were used as obtained without further purification: enzyme grade 4-(2-hydroxyethyl)-1-piperazineethanesulfonic acid (HEPES) (Aldrich), ferrous ammonium sulfate (Mallinckrodt), glycerol (Aldrich), $d_{3}$-glycerol (98 atom \% D, Cambridge Isotope Laboratories), and deuterium oxide (99.9 atom \% D, Aldrich). HEPES buffer (100 mM, pH 7.6) was degassed with at least 3 freeze-pump-thaw cycles at $10^{-3}$ Torr, while the apo protein samples (on ice) were degassed by gentle flushing with $\mathrm{O}_{2}$-scrubbed Argon gas on the Schlenk line for at least 30 minutes at $4{ }^{\circ} \mathrm{C}$. Solid ferrous ammonium sulfate was made anaerobic by pumping at $10^{-3}$ Torr for 30 minutes.

\section{Preparation of apo R2-WT, R2-Y122F/Y356F, and R2-W48A}

The apo form of R2-WT, Y122F/Y356F and W48A variants was overexpressed, purified, and characterized as previously reported. ${ }^{54-59}$ 


\section{Preparation of Intermediate X RFQ-MCD and RFQ-EPR samples}

The preparation of differous $\mathrm{R} 2$ cluster was carried out under strictly anaerobic conditions in an argon filled Vacuum Atmospheres Company (Hawthorne, CA) glove box $\left(<1 \mathrm{ppm} \mathrm{O}_{2}\right.$ ). Once apo protein samples $(1.0-1.6 \mathrm{mM})$ were deoxygenated on a Schlenk line at $4{ }^{\circ} \mathrm{C}$, they were preloaded with 3.3-3.5 equivalents of $\mathrm{Fe}^{\mathrm{II}}$ (ferrous ammonium sulfate) dissolved in an anaerobic solution of $5 \mathrm{mM} \mathrm{H}_{2} \mathrm{SO}_{4}$ (neutralized with excess buffer), both with and without 5 $\mathrm{mM}$ ascorbate. The samples were allowed to equilibrate for 5 minutes prior to loading into a $\mathrm{RFQ}$ syringe. The second RFQ syringe was loaded with an $\mathrm{O}_{2}$-saturated $100 \mathrm{mM}$ HEPES buffer $\left(1.5 \mathrm{mM} \mathrm{O}_{2}, 4{ }^{\circ} \mathrm{C}\right)$. All RFQ samples were prepared using Update Instruments System 1000 (Madison, WI) equipped with a Wiskind Grid Mixer and a spraying nozzle. Intermediate $\mathrm{X}$ was generated by quenching $20-50 \mu \mathrm{L}$ of the anaerobic diferrous R2-WT, R2-Y122F/Y356F, and $\mathrm{R} 2$-W48A enzyme against an equal volume of $\mathrm{O}_{2}$-saturated $100 \mathrm{mM}$ HEPES buffer, $\mathrm{pH}$ $=7.6$. This step was repeated multiple times to accumulate enough sample for MCD and EPR. The samples were freeze-quenched by spraying directly into liquid nitrogen or into liquid nitrogen cooled isopentane at $-140^{\circ} \mathrm{C}$ using appropriate reaction times (100-125 ms for R2WT at $5{ }^{\circ} \mathrm{C}, 70-100 \mathrm{~ms}$ at $11^{\circ} \mathrm{C}$ for R2-Y122F/Y356F, and $350-450 \mathrm{~ms}$ at $5{ }^{\circ} \mathrm{C}$ for R2-W48A). These aging reaction times used for trapping $\mathrm{X}$ were chosen based on previous stopped-flow kinetic studies. ${ }^{57-59}$ The samples of R2-W48A variant also contained $10 \%$ glycerol. The best results were achieved by freeze-quenching $\sim 20-50 \mu \mathrm{L}$ of the reaction mixture (diferrous protein samples and $\mathrm{O}_{2}$-saturated $100 \mathrm{mM}$ HEPES buffer, $\mathrm{pH}=7.6$ ). A wide mouth shallow liquid nitrogen container was used for quenching the samples directly in liquid nitrogen by placing the spraying nozzle $\sim 5 \mathrm{~mm}$ above the surface of the liquid nitrogen. The reaction was initiated immediately upon placing the spraying nozzle in its position. After mixing, samples were ejected rapidly from the spray nozzle, freezing before rising to the surface of the liquid nitrogen (the samples came into contact with the walls of dewar only after freezing). The frozen samples are small, flat ice crystals ( $\sim 2-3 \mathrm{~mm}$ in size; in contrast samples frozen in chilled isopentane formed a slurry). Higher ram velocities (up to $3.2 \mathrm{~cm} / \mathrm{s}$ ) produced the best quality crystals. The reproducibility was verified by repeating the experiment for each sample numerous times (all the spectra shown are a result of at least eight independent experiments). Freezing samples of $\mathrm{R} 2$ in chilled isopentane $\left(-140^{\circ} \mathrm{C}\right)$ led to the formation of poor glasses (with light depolarization of $~ 10-15 \%$ ) that limit the measurements of quantitative MCD spectral data. However, MCD spectra collected for corresponding samples frozen in liquid $\mathrm{N}_{2}$ and isopentane were identical (see Figures S3 and S4 in Supporting Information). RFQ frozen samples required for EPR analysis were packed into $4 \mathrm{~mm}$ quartz EPR tubes using long packers. The protocol for generation of an RFQ-MCD sample was described previously. ${ }^{38}$ In brief, the frozen crystals of the intermediate were crushed into a fine powder in a container immersed in liquid nitrogen and then mixed thoroughly with glycerol (pre-measured volume) at $-30^{\circ} \mathrm{C}$ in dry ice/ethanol bath until a homogeneous sample was obtained. To ensure homogeneity of the RFQ-MCD samples, the light beam in the MCD experiments was focused on at least ten different regions of each MCD sample glass and independent spectra were recorded. The MCD cell was carefully assembled on dry ice (two brass pieces with the $3.2 \mathrm{~mm}$ neoprene spacer and two infrasil quartz disks) with the intermediate frozen ice crystals/glycerol mixed paste being distributed evenly over the quartz disk of the MCD cell. The paste of intermediate $\mathrm{X}$ was then sandwiched between the two quartz disks and the cell quickly frozen in liquid nitrogen. All RFQ-MCD samples of intermediate $\mathrm{X}$ contained $\sim 60-70 \%$ glycerol and the final samples ranged in Fe concentration from $0.3-0.8 \mathrm{mM}$. The whole MCD sample preparation took on average 2-3 minutes. The stability of X in R2-WT and the two R2 variants was tested by monitoring the EPR signal of $\mathrm{X}$ over a 2-15 minute time course at $-30{ }^{\circ} \mathrm{C}$ since all RFQ-MCD sample were prepared at this temperature. 


\section{RFQ-EPR Experiments}

All X-band $(9.3 \mathrm{GHz})$ EPR spectra were obtained with a Bruker ER 220-D-SRC spectrometer equipped with an Air Products Model LTR Helitran liquid helium transfer refrigerator and a Lake Shore Cryotronics temperature controller model DTC-500 and an ESR-900 helium flow cryostat. The EPR signals were monitored at different temperatures ranging from $100-3 \mathrm{~K}$ using an ESR-900 cryostat and an external vacuum pump for temperatures below $4.2 \mathrm{~K}$. Specific sample conditions and spectrometer conditions are given in figure legends. Spin quantitation of EPR samples was determined from integrated EPR signal intensities using 1 $\mathrm{mM}$ copper perchlorate as a standard.

\section{RFQ-MCD Spectroscopy}

MCD spectra were recorded on JASCO J810 (UV-visible region) and J200 (NIR region) spectropolarimeters, each equipped with an Oxford Instruments SM4-7T superconducting magnetocryostat capable of magnetic fields up to $8 \mathrm{~T}$ and $7 \mathrm{~T}$ respectively and temperatures down to $1.4 \mathrm{~K}$, using an S-20 photomultiplier tube (UV-vis, $900-300 \mathrm{~nm}$ ) and a liquid-nitrogen cooled InSb solid state detector (NIR, 2000-600 nm). All MCD samples were checked for light depolarization effects by comparing the $\mathrm{CD}$ signal of a nickel (+)-tartrate solution placed before and after the sample. The depolarization was $<5 \%$ at $1.8 \mathrm{~K}$ for all samples. All LT absorption and MCD spectra were simultaneously fit to Gaussian band shapes using the program PeakFit version 4 (AISN Software Inc.). VTVH MCD data were fit using an in-house program, which minimizes the $\chi^{2}$ value by fitting the effective transition moment products with either a Simplex or a Levenberg-Marquadt algorithm with a spin Hamiltonian for the ground state Kramer's doublet $S=1 / 2.60$

\section{LT Absorption Spectroscopy}

Low temperature absorption spectra were collected on a Cary-17 double-beam spectrometer equipped with a Janis Super Vari-Temp liquid helium cryostat at $10.0 \mathrm{~K}$.

\section{Computational}

All density functional theory (DFT) calculations were performed on dual-CPU Pentium Xeon $2.8 \mathrm{GHz}$ work stations employing spin-unrestricted (SU) and broken symmetry (BS) methods ${ }^{61-63}$ to allow for a reasonable description of the electronic structure of antiferromagnetically coupled systems. All three models were geometry optimized using the Amsterdam Density Functional (ADF) program, version 2003.01 developed by Baerends et al. ${ }^{64,65}$ A triple- $\zeta$ Slater-type orbital basis set (ADF basis set TZP) with a single polarization function at the local density approximation of Vosko, Wilk, and Nusair ${ }^{66}$ with nonlocal gradient corrections of Becke and Perdew (BP86) ${ }^{67,68}$ were employed. The molecular orbitals were plotted using gOpenMol version 2.32 and Molden version 4.1. $\triangle \mathrm{SCF}$ and Slater transition state methods were employed using ADF. The Mulliken population analyses were performed using the AOMix ${ }^{69}$ and PyMolyze ${ }^{70}$ programs. Time-dependent DFT (TD-DFT) calculations were performed with the Gaussian 03 package. ${ }^{71}$ A 6-311G* basis-set was used for all atoms with the local density approximation of Vosko, Wilk, and Nusair ${ }^{66}$ and the nonlocal gradient corrections of Becke and Perdew (BP86). ${ }^{67,68}$ In all models, the single high-spin Fe / antiferromagnetic (AF) state was initially converged with smaller basis-sets (i.e. 3-21G*), which was used as the initial guess for larger basis-sets (i.e. 6-311G*). The high-spin AF state for all models was found to be lower in energy than the low-spin AF state. Complete coordinates of all the geometry-optimized models discussed in the text are included in Supporting Information (Tables S1-S3). 


\section{Results}

\subsection{EPR Characterization of RFQ Samples}

All the RFQ-MCD samples of $X$ used in the analysis were characterized by RFQ-EPR spectroscopy to establish the $\% \mathrm{X}$ and $\% \mathrm{Y} 122 \cdot$ present. Figure 2 shows the comparison of the EPR spectra of X trapped in R2-WT and the two variants Y122F/Y356F and W48A, with their corresponding decayed $\mathrm{X}$ spectra. The characteristic signal of $\mathrm{X}$ observed in both R2-WT (Figure 2A) and the double variant (Figure 2C) is typical of a system with the ground state $S_{\text {tot }}=1 / 2$ and nearly isotropic $\mathrm{g}=2.0$ value. The aging times $(110-125 \mathrm{~ms})$ used for formation of $X$ in the R2-WT enzyme allowed for maximum amounts of $X$ to be formed with as little of decayed products as possible, but variable amounts of the reaction product, $\mathrm{Y} 122 \cdot$ were also detected (from $28-42 \%$ ). This was unavoidable for the R2-WT reaction since the MCD sample manipulations were carried out at $-30^{\circ} \mathrm{C}$ following RFQ trapping in order to obtain goodquality optical samples of $\mathrm{X}$. The $\mathrm{X}$ intermediate was found to decay faster in the R2-WT enzyme than in the two $\mathrm{R} 2$ variants.

Figure 2A shows the EPR spectrum of $\mathrm{X}$ in R2-WT containing $62 \% \pm 2 \% \mathrm{X}$ and $38 \% \pm 2 \%$ Y122. The 10-minute time-point of the reaction was used as a reference spectrum of magnetically isolated $\mathrm{Y} 122 \cdot$ (see Figure 2B). A freeze-quenched sample from the reaction of double variant with $\mathrm{O}_{2}$ was used as a reference sample for $\mathrm{X}$ as its kinetics of $\mathrm{X}$ formation and decay are such that pure $\mathrm{X}$ accumulates in high yields (1.4 equiv) without contamination from Y122• (Figure 2C). A slight excess of dithionite was used to eliminate any $\mathrm{W}_{4} 8^{+\bullet}$ species, which can accumulate by supplying an additional electron to form $\mathrm{X}$ under reductant-limiting conditions. The EPR spectrum of decayed $\mathrm{X}$ in the double variant is characteristic of a tyrosyl radical (Figure 2D). Finally, the EPR spectrum of $X$ in the W48A variant exhibits a unique feature with a broader $\mathrm{g}=2.0$ signal (Figure 2E). This EPR signal is attributed to a coupled biradical species containing both $\mathrm{X}$ and $\mathrm{Y} 122 \cdot$. This EPR spectrum is not the same as magnetically isolated intermediate $\mathrm{X}$ or isolated $\mathrm{Y} 122 \bullet$ indicating a weak interaction of the two paramagnetic species, $X$ and $Y 122 \cdot 54,72$ Subsequent decay of X-Y122• in W48A gives an EPR spectrum characteristic of isolated $\mathrm{Y} 122 \bullet$ (Figure 2F). EPR spin quantitation for the $\mathrm{W} 48 \mathrm{~A}$ variant indicates that $\sim 0.25$ equivalents of stable $\mathrm{Y} 122 \bullet$ are formed at the end of the reaction.

\subsection{Low-Temperature Absorption and MCD Spectroscopy of Intermediate X}

The low-temperature (LT) absorption spectra of X in R2-WT, R2-Y122F/Y356F, and R2W48A are shown in Figure 3. The predominant spectral features of intermediate $\mathrm{X}$ in the 10 $\mathrm{K}$ absorption spectrum occur in the high-energy region centered at $\sim 27800 \mathrm{~cm}^{-1}(\varepsilon \approx 2800$ $\left.\mathrm{M}^{-1} \mathrm{~cm}^{-1}\right)$ with a steep increase in intensity starting at $\sim 31000 \mathrm{~cm}^{-1}\left(\varepsilon \approx 4000 \mathrm{M}^{-1} \mathrm{~cm}^{-1}\right)$. There is also a rather weak tailing absorption feature at $\sim 20000 \mathrm{~cm}^{-1}\left(\varepsilon \approx 900 \mathrm{M}^{-1} \mathrm{~cm}^{-1}\right)$. In the case of the R2-W48A variant, there is also a sharp feature in the absorption spectrum at $\sim 24000$ $\mathrm{cm}^{-1}$ (Figure 3C) indicative of the presence of Y122• that is weakly spin coupled to X (vide supra). A smaller similar sharp feature is present in the absorption spectrum of R2-WT-X (Figure 3A), but here the amount of Y122 • species correlates with the amount of decayed X quantitated by EPR. Consistent with the EPR results in Figure 2, no sharp Y122• feature is present in the absorption spectrum of $\mathrm{X}$ for the $\mathrm{R} 2-\mathrm{Y} 122 \mathrm{~F} / \mathrm{Y} 356 \mathrm{~F}$ variant.

The $10 \mathrm{~K}$ absorption spectra of decayed $\mathrm{X}$ in R2-WT reaction and the two R2 variants are shown in Supporting Information (Figure S1). Decay of X generates a $\mu$-oxo bridged diferric cluster (broad absorption bands at $\sim 31250$ and $\sim 27000 \mathrm{~cm}^{-1}$ ) and the tyrosyl radical characterized by a sharp feature at $24330 \mathrm{~cm}^{-1}$. The high-energy absorption features of $\mathrm{X}$ are difficult to differentiate from those attributed to decayed X (particularly in WT) since both X and the diferric cluster absorb in the region of $\sim 27000-28000 \mathrm{~cm}^{-1}$ and the primary difference 
lies in the kinetics of the band formation and disappearance. However, MCD spectroscopy allows for a complete differentiation of these bands, as the diferric cluster is not paramagnetic and will not exhibit intense LT MCD features ( $C$-terms). Since intermediate $\mathrm{X}$ is paramagnetic, it shows an intense VTVH MCD signal.

Figure 4 displays the low-temperature MCD spectra of X in R2-WT, R2-Y122F/Y356F, and $\mathrm{R} 2-\mathrm{W} 48 \mathrm{~A}$. Figures 3B and 4B reproduce the absorption and MCD data obtained previously on $\mathrm{R} 2-\mathrm{Y} 122 \mathrm{~F} / \mathrm{Y} 356 \mathrm{~F}-\mathrm{X}$. There is a good correlation of band signs, energies, and shapes between the three MCD spectra of intermediate $\mathrm{X}$, and these can be correlated to the features observed in the absorption spectra. The simultaneous Gaussian fitting of the MCD with the LT absorption data results in 10 electronic transitions in the region from 5000 to $33300 \mathrm{~cm}^{-1}$ (Table 1, note that no transitions are observed in the NIR region below $14000 \mathrm{~cm}^{-1}$ associated with intermediate X). The LT-MCD data show an apparent large deviation from the MCD "sum rule" (equal and opposite signed LT-MCD intensity) and the deviation requires spinorbit coupling of low-lying excited states into the ground state. The MCD and absorption spectra have been divided into three regions based on the intensities and $C_{0} / D_{0}$ ratios for $\mathrm{X}$ in R2-WT and the two R2 variants. $C_{0} / D_{0}$ ratios $\left(C_{0} / D_{0}=k_{\mathrm{B}} T / \mu_{\mathrm{B}} B(\Delta \varepsilon / \varepsilon)_{\max }\right.$ where $k_{\mathrm{B}}$ is the Boltzmann's constant, $\mu_{\mathrm{B}}$ is the Bohr magneton $\left(k_{\mathrm{B}} / \mu_{\mathrm{B}}=1.489 \mathrm{~K}^{-1} \mathrm{~T}^{-1}\right), T$ is the temperature in $\mathrm{K}, \varepsilon$ is the molar absorptivity in $\mathrm{M}^{-1} \mathrm{~cm}^{-1}$, and $\Delta \varepsilon$ is the MCD intensity maximum in $\mathrm{M}^{-1}$ $\mathrm{cm}^{-1}$ recorded in the linear $1 / T$ region) are used to differentiate metal-based ligand field $(\mathrm{d} \rightarrow$ $\mathrm{d}$ transitions) from ligand-based charge transfer (CT) transitions. Since the spin-orbit coupling constant for the $\mathrm{Fe}^{\mathrm{IV}}$ is much higher $\left(\xi_{\mathrm{Fe}} \mathrm{IV}=520 \mathrm{~cm}^{-1}\right)$ than for the oxygen $\left(60-70 \mathrm{~cm}^{-1}\right)$ or nitrogen $\left(50 \mathrm{~cm}^{-1}\right)$ ligands, the $\mathrm{d} \rightarrow \mathrm{d} \mathrm{LF}$ transitions are expected to have higher $C_{0} / D_{0}$ ratios as they are centered on the $\mathrm{Fe}^{\mathrm{IV}}$ of intermediate $\mathrm{X} .{ }^{73,74}$ Region I (bands 1-3 in Figures 3 and 4) displays the most intense features in the MCD spectrum of $\mathrm{X}$, with high $C_{0} / D_{0}$ ratios from 0.012-0.050 (i.e. high MCD, but weak absorption intensity). Thus, these three bands (bands 1-3) can be assigned as the spin-allowed ligand field transitions of the high-spin $\mathrm{Fe}^{\mathrm{IV}}$, supporting significant $\mathrm{Fe}^{\mathrm{IV}}$ character in the paramagnetic center of $\mathrm{X}$.

Region II (bands 4 and 5) involves spin-forbidden LF transitions ( $\Delta S=1$ spin-flip transitions). These sharp but weak MCD bands are observed between 23000 and $24500 \mathrm{~cm}^{-1}$ and do not vary over any of the MCD spectra for X in R2-WT and the two variants. Based on the energy and bandwidth these transitions could be assigned to either a spin flip on the $\mathrm{Fe}^{\mathrm{III}}$ or $\mathrm{Fe}^{\mathrm{IV}}$

center. The ligand field independent spin-forbidden transitions gain some intensity in coupled dimers through the exchange interaction associated with the bridging ligand (vide infra). The ligand field independent spin flips of an $\mathrm{Fe}$ III center (involving the ${ }^{6} \mathrm{~A}_{1} \rightarrow{ }^{4} \mathrm{~A}_{1},{ }^{4} \mathrm{E}$ transitions) are well known to occur in the region of $\sim 21000 \mathrm{~cm}^{-1}$ in mono- $\mu$-oxo ferric dimers and in the region $17700-19100 \mathrm{~cm}^{-1}$ for bis- $\mu$-oxo ferric dimers. ${ }^{75}$ Bands 4 and 5 are too high in energy to be attributed to $\mathrm{Fe}^{\mathrm{III}}$ spin flips and are thus assigned as ligand field independent spinforbidden transitions $\left({ }^{5} \mathrm{E} \rightarrow{ }^{3} \mathrm{~T}_{1}\right)$ on the $\mathrm{Fe}^{\mathrm{IV}}$.

Region III (bands 6-10) involves transitions at $\geq 25000 \mathrm{~cm}^{-1}$ with low $C_{0} / D_{0}$ ratios from 0.004 -0.011 (i.e. weak MCD, but strong absorption) and are thus assigned as oxo to $\mathrm{Fe}^{\mathrm{IV}}$ and oxo to $\mathrm{Fe}^{\mathrm{III}} \mathrm{CT}$ transitions. Oxo $\rightarrow \mathrm{Fe}^{\mathrm{IV}}$ transitions are anticipated to be at a lower energy relative to oxo $\rightarrow \mathrm{Fe}^{\mathrm{III}} \mathrm{CT}$ due to the increased $Z_{\text {eff. }}$. Modestly intense oxo $\rightarrow \mathrm{Fe}^{\mathrm{III}} \mathrm{CT}$ transitions in mono- $\mu$-oxo ferric dimers are observed at $\geq 28000 \mathrm{~cm}^{-1} .{ }^{75}$ Jorgensen's optical electronegativity differences between the donor and acceptor orbitals can be used to estimate charge transfer transition energies. ${ }^{76}$ Using rough estimates of optical electronegativities $\left(\chi_{\text {opt }}\right)$ for high-spin $\mathrm{Fe}^{\mathrm{IV}}\left(\chi_{\mathrm{opt}}\left(\mathrm{Fe}^{\mathrm{IV}}\right)=2.8-3.2\right)$ and a bridging oxo ligand $\left(\chi_{\mathrm{opt}}\left(\mathrm{O}^{2-}\right)=3.6-3.8\right)$ in the following expression:

$v_{\mathrm{CT}}=30000\left[\chi_{\text {opt }}\left(\mathrm{O}^{2-}\right)-\chi_{\text {opt }}\left(\mathrm{Fe}^{\mathrm{IV}}\right)\right] \mathrm{cm}^{-1}(\mathrm{LMCT})$, 
calculates the oxo $\rightarrow \mathrm{Fe}^{\mathrm{IV}} \mathrm{CT}$ transitions in the range of $24000-28000 \mathrm{~cm}^{-1}$. The same expression for high-spin $\mathrm{Fe}^{\mathrm{III}}\left(\chi_{\text {opt }}\left(\mathrm{Fe}^{\mathrm{III}}\right)=2.5-2.7\right)$ gives oxo $\rightarrow \mathrm{Fe}^{\mathrm{III}} \mathrm{CT}$ transitions in the range of $27000-33000 \mathrm{~cm}^{-1}$. Therefore, it is reasonable to assume that bands 6 and 7 and possibly 8 in the MCD spectrum of $\mathrm{X}$ can be assigned as oxo $\rightarrow \mathrm{Fe}^{\mathrm{IV}} \mathrm{CT}$ transitions and that the higher energy transitions could correspond to oxo $\rightarrow \mathrm{Fe}^{\mathrm{III}} \mathrm{CT}$ transitions. However, this approach assumes the $\mathrm{Fe}^{\mathrm{III}}$-oxo and the $\mathrm{Fe}^{\mathrm{IV}}$-oxo bonding are mutually exclusive and neglects covalency effects over the entire $\mathrm{Fe}^{\mathrm{III}}-\mathrm{O}-\mathrm{Fe}^{\mathrm{IV}}$ dimer unit (vide infra).

The absorption and MCD spectra of decayed X in R2-WT and the two variants are given in Supporting Information (Figure S1 and S2). These spectra are distinctly different from those of intermediate $\mathrm{X}$ in Figure 4, and provide additional evidence for the assignment of the spectral features in Figure 4 as due solely to $\mathrm{X}$. The tyrosyl radical and $\mu$-oxo bridged diferric cluster are the major decay products of $\mathrm{X}$ with tyrosyl radical being the primary paramagnetic component. The MCD spectrum of decayed X in R2-WT enzyme exhibits a feature at $\sim 24300$ $\mathrm{cm}^{-1}$ due to tyrosyl radical formation (note that this feature is different from that observed in this energy region for X). There is also a broad negative feature observed at $\sim 20000 \mathrm{~cm}^{-1}$ which is due to some paramagnetic decay contribution, not yet identified. The high energy band at $\sim 30000 \mathrm{~cm}^{-1}$ is temperature independent ( $B$-term MCD intensity) and arises from the diamagnetic contribution of the oxo-bridged diferric cluster. The decayed X of the R2-Y122F/ Y356F variant exhibits the characteristic tyrosyl radical feature at $\sim 24300 \mathrm{~cm}^{-1}$ and the highenergy band at $\sim 30000 \mathrm{~cm}^{-1}$ which is also temperature independent. $28-30$

The decayed X in R2-W48A variant is characterized by a broad negative feature at 15000 $20000 \mathrm{~cm}^{-1}$ and a broad positive, temperature independent feature at $25000-30000 \mathrm{~cm}^{-1}$ which is associated with the diamagnetic decayed diferric cluster. The tyrosyl radical feature is not obvious in this spectrum as it is very weak and masked by the broad negative and positive features. Importantly, the MCD spectra of decayed X in Figure S2 clearly display different features from those attributed to X. Given that the spin-orbit coupling constant for the tyrosyl radical is small, this at most contributes a small feature to the MCD spectrum of decayed X. The MCD features of intermediate $X$ assigned as spin flips (bands 4 and 5) in Figure 4 are present even after subtraction of the tyrosyl radical contribution in R2-WT enzyme and are present in the MCD spectrum of $\mathrm{Y} 122 \mathrm{~F} / \mathrm{Y} 356 \mathrm{~F}-\mathrm{X}$, which does not contain a contribution from the tyrosyl radical (from EPR).

Finally, it is important to note for Figures 3 and 4, that while R2-WT-X and R2-Y122F/Y356F$\mathrm{X}$ exhibit similar energies for the three spin allowed d-d transitions of the $\mathrm{Fe}^{\mathrm{IV}}$ center, the d$\mathrm{d}$ transitions in the R2-W48A-X (Figure 4C) are shifted to higher energy and display a smaller energy separation of bands 1-3.

\subsection{Variable Temperature Variable Field (VTVH) MCD}

VTVH-MCD data were collected for R2-WT and the two variant forms of intermediate X. R2$\mathrm{Y} 122 \mathrm{~F} / \mathrm{Y} 356 \mathrm{~F}$ X displays the most well resolved MCD transitions for VTVH analysis, Figure 4. The VTVH-MCD data for R2-Y122F/Y356F X were collected at four different bands as presented in Figure 5. All the saturation magnetization curves (MCD intensity as a function of $\beta H / 2 k T$ ) recorded at various magnetic fields and at a series of temperatures from 1.8-40 K overlay within standard deviation and thus do not display any nesting behavior. These isotherms are dependent on the $S_{\text {tot }}$ of the ground state and were fit using the EPR parameters of $\mathrm{X}\left(\mathrm{g}_{\|}=2.006\right.$ and $\left.\mathrm{g}_{\perp}=1.994\right)$, resulting in spin Hamiltonian parameters characteristic for an isotropic ground state with an isolated $S=1 / 2$ for all bands.

The temperature dependence of the full MCD spectra of X for both the R2-Y122F/Y356F and R2-W48A variants, ranging from $1.8 \mathrm{~K}$ to $170 \mathrm{~K}$ at high field $(7 \mathrm{~T})$ were collected. Figure 6 shows the 7-T MCD spectrum of intermediate $\mathrm{X}$ in the $\mathrm{R} 2-\mathrm{Y} 122 \mathrm{~F} / \mathrm{Y} 356 \mathrm{~F}$ variant over the 
energy region of $17000-33000 \mathrm{~cm}^{-1}$ between $1.8 \mathrm{~K}$ and $115 \mathrm{~K}$. The variable temperature MCD data exhibit typical $C$-term behavior with the signal intensity decreasing as $1 / \mathrm{T}$ with increasing temperature. This behavior is observed for all the spectral features of intermediate $\mathrm{X}$.

Since the MCD signal intensity of all bands decreases linearly as $1 / T$ for temperatures up to $115 \mathrm{~K}$, it can be concluded that there is no thermally accessible low-lying excited sublevel of the $S_{\text {tot }}=1 / 2$ ground state of intermediate $X$. The energy splitting of the ground state is described by a phenomenological spin Hamiltonian, $H=-2 J \mathbf{S}_{1} \cdot \mathbf{S}_{2}$, where $\mathbf{S}$ represents the spin on each iron and $J$ is the exchange coupling constant. A two-level Boltzmann distribution yields a $\Delta \mathrm{E}>110 \mathrm{~cm}^{-1}$ between the two levels with a population of $<20 \%$ population of the excited state, at a temperature of $115 \mathrm{~K}$. The lack of an observable thermally accessible (at $115 \mathrm{~K}$ ) $S_{\text {tot }}=3 / 2$ excited state indicates a strong antiferromagnetically coupled $\mathrm{Fe}^{\mathrm{III}}-\mathrm{O}-\mathrm{Fe}^{\mathrm{IV}}$ dimer, giving a lower-limit on the magnitude of the exchange coupling of $-3 J>110 \mathrm{~cm}^{-1}$.

\section{Analysis}

Our preliminary report on the RFQ-MCD of X in $\mathrm{Y} 122 \mathrm{~F} / \mathrm{Y} 356 \mathrm{~F}$ used a quantitative assessment of the $\mathrm{Fe}^{\mathrm{IV}}$ ligand field to support that intermediate $\mathrm{X}$ contained a single oxo bridge, ${ }^{38}$ consistent with ${ }^{17} \mathrm{O}-\mathrm{O}_{2}$ and $\mathrm{H}_{2} \mathrm{O}$ ENDOR data. ${ }^{40}$ The ligand field analysis argued against the possibility of a bis- $\mu$-oxo core structure due to the larger equatorial ligand field oxo bonds which leads to a larger splitting of the $\mathrm{Fe}^{\mathrm{IV}} \mathrm{d}$-d transitions compared with the mono- $\mu$-oxo splitting. The larger splitting of the bis- $\mu$-oxo would shift the $\mathrm{Fe}^{\mathrm{IV}} \mathrm{d}$-d transitions to higher energy than the relatively low energy $\mathrm{d}$-d transitions observed in intermediate $\mathrm{X}$. These LF calculations were calibrated based on absorption and MCD data from mono- and bis- $\mu$-oxo binuclear Mn systems. $77-79$

This study extends the initial ligand field analysis to include covalency effects and $\pi$ - as well as $\sigma$-bonding interactions from the bridging oxo ligand(s) through the use of DFT calculations combined with perturbations on the spectral data of X in the two variants and WT (section 5). This computational approach was used to explore the electronic and geometric structure differences between three possible structural models for X (mono- $\mu$-oxo, $\mu$-oxo/ $\mu$-hydroxo and the bis- $\mu$-oxo bridged species). Furthermore, TD-DFT, Slater and $\Delta$ SCF transition state methods were used to calculate the $\mathrm{Fe}^{\mathrm{IV}} \mathrm{d}$-d transitions within these three models and correlate their energies and intensities to those observed by RFQ-MCD for intermediate $\mathrm{X}$ in the WT $\mathrm{R} 2$, as well as the structurally perturbed forms of $\mathrm{X}$ in the two variants (section 5).

\subsection{DFT: Geometry Optimizations}

Previous structural assignments for intermediate $X$ have primarily focused on either a monoor bis- $\mu$-oxo core structure, based on EPR, ${ }^{18}$ ENDOR, 39,40 EXAFS, ${ }^{37}$ Mössbauer $^{28}$ and $\mathrm{MCD}^{38}$ spectroscopies as well as DFT calculations. $33,42-49,51-53,80$ The $\mu$-oxo/ $\mu$-hydroxo core structure is also included here as it has been generated in diferric model complexes 81 as well as explored by DFT, ${ }^{51}$ but has not been considered thus far as a viable structure for intermediate $\mathrm{X}$. This structure would have one strong oxo bridge, but a short $\mathrm{Fe}-\mathrm{Fe}$ distance associated with two mono atomic bridging ligands, as observed in EXAFS. ${ }^{37}$ The tops of Figures $7-9$ display the three possible geometric core structures of intermediate $\mathrm{X}$ evaluated here: mono- $\mu$-oxo, $\left[\mathrm{Fe}^{\mathrm{III}}(\mu-\mathrm{O}) \mathrm{Fe}^{\mathrm{IV}}\right] ; \mu$-oxo $/ \mu$-hydroxo, $\left[\mathrm{Fe}^{\mathrm{III}}(\mu-\mathrm{O})(\mu-\mathrm{OH}) \mathrm{Fe}^{\mathrm{IV}}\right]$; and bis- $\mu$ oxo, $\left[\mathrm{Fe}^{\mathrm{III}}(\mu-\mathrm{O})_{2} \mathrm{Fe}^{\mathrm{IV}}\right]$, respectively.

While there is a small number of high-valent binuclear iron oxo model systems available, only one has been structurally characterized, ${ }^{82}$ and none of these models has the correct high-spin state for each iron as found in intermediate $\mathrm{X}$. Therefore, the computational models presented here were based on similar diferric and dimanganese model structures, with an effort to keep 
the non-oxo ligands identical. The mono- $\mu$-oxo structure was based on the structurally characterized $\left[\left(\mathrm{Fe}^{\mathrm{III}}\right)_{2}(\mu-\mathrm{O})\left([9] \mathrm{aneN}_{3}\right)_{2}\left(\mu-\mathrm{CH}_{3} \mathrm{CO}_{2}\right)_{2}\right]^{3+}$ complex of Wieghardt et al. ${ }^{83}$ The electronic structure of this complex consists of two high-spin $\mathrm{Fe}^{\mathrm{III}}(S=5 / 2)$ atoms antiferromagnetically coupled to yield an overall $S=0$ ground state. The DFT geometry optimization of this complex led to a final structure that paralleled the geometric and electronic structure of the actual complex. However, upon the computational removal of one electron from the geometry optimized $\mathrm{Fe}^{\mathrm{III}}{ }_{2}$ complex, the oxidized complex reoptimized to a low-spin $\mathrm{Fe}^{\mathrm{III}} S=1 / 2$ and low-spin $\mathrm{Fe}^{\mathrm{IV}} S=1$ antiferromagnetically coupled system. This result is consistent with the experimental electrochemical results for this oxidized complex, which yielded a 35:65 mixture of $S=1 / 2$ and $S=3 / 2$ species. ${ }^{84}$ The Mössbauer and EPR results from this complex were ambiguous as to the nature of the $\mathrm{Fe}^{\mathrm{IV}}$ spin-state.

The $\mu$-oxo/ $\mu$-hydroxo and bis- $\mu$-oxo models were based on the structurally characterized $\left[\mathrm{Mn}^{\mathrm{III}}(\mu-\mathrm{O})_{2} \mathrm{Mn}^{\mathrm{IV}}\left([9] \mathrm{aneN}_{3}\right)_{2}\left(\mu-\mathrm{CH}_{3} \mathrm{CO}_{2}\right)\right]^{2+}$ complex and differ by one proton bound to an oxo bridge. ${ }^{79}$ Similar spin-state issues (these complexes energetically optimized to a low-spin state on each iron) were also encountered for these models. The $\mathrm{Fe}^{\mathrm{IV}}$ spin-state plays an important role in defining the geometric and electronic structure of the complex, which determines its reactivity. Therefore, a weaker ligand set was chosen for all three structures to maintain high-spin states on both irons and to preserve their structural consistency. The nitrogen-based [9] $\mathrm{aneN}_{3}$ ligand set was replaced with a weaker oxygen-based 9-crown-3 ether ligand set. This ligand change resulted in the three computational models shown in Figures 7-9. With this ligand modification, all three models geometry optimized to minimum energy complexes, which maintained high-spin $\mathrm{Fe}^{\mathrm{III}} S=5 / 2$ antiferromagnetically coupled to a highspin $\mathrm{Fe}^{\mathrm{IV}} S=2$ to yield $S_{\text {tot }}=1 / 2$ ground states. The mono- $\mu$-oxo structure was the only complex which needed to be geometry optimized to the ferromagnetic $S_{\text {tot }}=9 / 2$ state first, and then reoptimized under broken symmetry (BS) to converge to the lower energy antiferromagnetically coupled high-spin state. The other structures were also geometry optimized to ferromagnetically coupled $S_{\text {tot }}=9 / 2$ states, which were at higher energy than the $S_{\text {tot }}=1 / 2$ for all three complexes.

\subsection{DFT: Ground State Geometric and Electronic Structure}

Figures 7, 8 and 9 display a geometry optimized structure and energy level diagram for each of the three possible structural models of intermediate X. The comparison of these calculated structures to the experimental data of intermediate $\mathrm{X}$ provides a reasonable basis for the evaluation of the geometric and electronic structure of X.

While all three structures maintain a high-spin $\mathrm{Fe}^{\mathrm{III}}(S=5 / 2)$ and $\mathrm{Fe}^{\mathrm{IV}}(S=2)$ antiferromagnetically coupled to yield an $S_{\text {tot }}=1 / 2$ ground state, their geometric and electronic structures vary. The mono- $\mu$-oxo and $\mu$-oxo/ $\mu$-hydroxo structures display the shorter $\mathrm{Fe}^{\mathrm{IV}}$ $\mathrm{O}_{\text {oxo }}$ distance of $1.70 \AA$, while the bis- $\mu$-oxo structure displays two $\mathrm{Fe}^{\mathrm{IV}}-\mathrm{O}_{\text {oxo }}$ distances of $1.73 \AA$. However, all three bridged structures have longer distances than the experimentally well defined (TMC-NCMe)Fe $\mathrm{e}^{\mathrm{IV}}=\mathrm{O}(S=1)$ complex with a terminal oxo, which has a relatively short $\mathrm{Fe}^{\mathrm{IV}}-\mathrm{O}_{\text {oxo }}$ distance of $1.65 \AA .{ }^{85} \mathrm{The}^{\mathrm{Fe}} \mathrm{e}^{\mathrm{III}}-\mathrm{O}-\mathrm{Fe}^{\mathrm{IV}}$ angle decreases from the mono- $\mu$ oxo to the $\mu$-oxo $/ \mu$-hydroxo to the bis- $\mu$-oxo $; 123^{\circ}, 104^{\circ}$, and $92^{\circ}$ respectively. The $\mathrm{Fe}^{\mathrm{III}}-$ $\mathrm{Fe}^{\mathrm{IV}}$ distance also decreases from the mono- $\mu$-oxo to the $\mu$-oxo/ $\mu$-hydroxo to the bis- $\mu$-oxo; $3.12 \AA, 2.82 \AA$, and $2.63 \AA$ respectively. Parallel to the $\mathrm{Fe}^{\mathrm{IV}}-\mathrm{O}_{\text {oxo }}$ distance, the $\mathrm{Fe}^{\mathrm{III}}-\mathrm{O}_{\text {oxo }}$ distance also lengthened from the mono- $\mu$-oxo to the $\mu$-oxo/ $\mu$-hydroxo to the bis- $\mu$-oxo structures; $1.85 \AA, 1.87 \AA$, and $1.91 \AA$ respectively.

The geometric differences among the three structures are reflected in their electronic structures. Each electronic structure is given by the energy level diagram at the bottom of Figures 7, 8 and 9. These figures display the ground state occupied and unoccupied d-orbital energy levels for each iron. The $\mathrm{Fe}^{\mathrm{IV}}$ has five $\alpha$ unoccupied, four $\beta$ occupied and one $\beta$ unoccupied d orbitals. 
The $\mathrm{Fe}^{\mathrm{IV}} 10 D \mathrm{q}$ values (based on the average energy separation between the $\mathrm{d}-\sigma^{*}\left(\mathrm{xy}, \mathrm{z}^{2}\right)$ and $\mathrm{d}-\pi^{*}\left(\mathrm{xz}, \mathrm{yz}\right.$ and $\left.\mathrm{x}^{2}-\mathrm{y}^{2}\right)$ manifolds for the $\mathrm{Fe}^{\mathrm{IV}} \beta$-orbitals) are $16100 \mathrm{~cm}^{-1}, 14100 \mathrm{~cm}^{-1}$ and 13 $000 \mathrm{~cm}^{-1}$ for the mono- $\mu$-охо, $\mu$-oxo/ $\mu$-hydroxo and the bis- $\mu$-oxo structures respectively. The three $10 D$ q values vary by only $~ 3000 \mathrm{~cm}^{-1}$. The energy splittings of the $\mathrm{Fe}^{\mathrm{IV}} \mathrm{d}-\sigma^{*}$ orbitals are also fairly similar with energies of $11300 \mathrm{~cm}^{-1}, 11300 \mathrm{~cm}^{-1}$, and $11500 \mathrm{~cm}^{-1}$ for the mono$\mu$-oxo, $\mu$-oxo/ $\mu$-hydroxo and bis- $\mu$-oxo structures respectively. Importantly, the energy splittings of the $\mathrm{Fe}^{\mathrm{IV}} \mathrm{d}-\pi^{*}$ manifold decreased significantly from the mono- $\mu$-oxo to $\mu$-oxo/ $\mu$ hydroxo to bis- $\mu$-oxo; $8100 \mathrm{~cm}^{-1}, 3500 \mathrm{~cm}^{-1}$, and $2300 \mathrm{~cm}^{-1}$ respectively.

The Fe $\mathrm{F}^{\mathrm{III}} \mathrm{d}$-manifolds displayed similar energy changes among the three structures. Interestingly, the $\mathrm{Fe}^{\mathrm{III}}$ and $\mathrm{Fe}^{\mathrm{IV}}$ d-manifolds appear in nearly the same energy region for all three structures, which reflects a significant amount of covalency within the $\mathrm{Fe} \mathrm{e}^{\mathrm{III}}-\mathrm{O}-\mathrm{Fe}^{\mathrm{IV}}$ unit (vide infra).

The $\mathrm{Fe}^{\mathrm{IV}}$ d-manifold energy differences reflect changes in the bonding interactions between the $\mathrm{Fe}^{\mathrm{IV}}$ and the core oxo and hydroxo ligand(s). Due to a significant amount of spinpolarization in the $\beta$-occupied $\mathrm{Fe}^{\mathrm{IV}} \mathrm{d}$-orbitals, these differences are most easily correlated in the $\alpha$-unoccupied $\mathrm{Fe}^{\mathrm{IV}}$ d-orbitals, which reflect the un-compensated bonding interactions of the $\mathrm{Fe}^{\mathrm{IV}} \beta$-occupied orbitals. Figure 10 summarizes these energy differences, also see Tables 2 and 3. Supplementary Figures S5 and S6 include contours that further dissect the $\mathrm{Fe}^{\mathrm{IV}}$ $\mathrm{O}_{\text {oxo }}$ bonding interactions that give rise to these energy differences. Figure 10 and Tables 2 and 3 also include a hypothetical mononuclear $\mathrm{Fe}^{\mathrm{IV}}=\mathrm{O}$ high-spin $S=2$ system as a reference. 86,87 Figure 10 displays the large energy splitting between the mononuclear $\mathrm{Fe}^{\mathrm{IV}} \mathrm{d}-\sigma$ manifold. This is due to dominant $\mathrm{Fe}^{\mathrm{IV}}-\mathrm{O}_{\text {oxo }} \sigma$-bonding along the z-axis versus the relatively weaker equatorial ligand field along the $\mathrm{x}$ and $\mathrm{y}$ axes. This is reflected in the large amount of oxo character in the $\mathrm{d}\left(\mathrm{z}^{2}\right)$ orbital, Tables 2 and 3. In Figure 10b-d and S5, all three binuclear models display a smaller splitting between their $\mathrm{Fe}^{\mathrm{IV}} \mathrm{d}-\sigma^{*}$ orbitals, consistent with their longer $\mathrm{Fe}^{\mathrm{IV}}$ $\mathrm{O}_{\text {oxo }}$ bond lengths. Also, the bent $\mathrm{Fe}{ }^{\mathrm{III}}-\mathrm{O}-\mathrm{Fe}^{\mathrm{IV}}$ angle of $123^{\circ}$ in the mono- $\mu$-oxo and $104^{\circ}$ in the $\mu$-oxo/ $\mu$-hydroxo dimers weakens the $\mathrm{Fe}^{\mathrm{IV}}-\mathrm{Op}_{\mathrm{z}}$ bond and lowers the energy of the $\mathrm{d}\left(\mathrm{z}^{2}\right)$ orbital in both structures relative to the mononuclear case. (Note that different axis systems are used for the different structures. The $\mathrm{z}$-axis is directed along the $\mathrm{Fe}^{\mathrm{IV}}$-oxo bond in the mononuclear, binuclear mono- $\mu$-oxo and binuclear $\mu$-oxo/ $\mu$-hydroxo cases. The $\mathrm{z}$-axis in the binuclear bis- $\mu$-oxo case is perpendicular to the $\mathrm{Fe}^{\mathrm{IV}}-(\mathrm{O})_{2}$ plane. The $\mathrm{x}$ and $\mathrm{y}$ axes bisect the ligand $-\mathrm{Fe}$ bonds in the binuclear systems.) The bis- $\mu$-oxo structure has two oxo ligands that impose a stronger equatorial ligand field and increase the energy of the $d(x y)$ orbital. Overall, the $\mathrm{Fe}^{\mathrm{IV}} \mathrm{d}-\sigma^{*}$ splitting is smaller for the binuclear complexes due to the bridged bonding of the oxo that results in a weaker $\mathrm{Fe}^{\mathrm{IV}}-\mathrm{Op}_{\mathrm{z}}$ bond. The bent nature of the $\mathrm{Fe}^{\mathrm{III}}-\mathrm{O}-\mathrm{Fe}^{\mathrm{IV}}$ unit also weakens the $\mathrm{Fe}^{\mathrm{IV}}-\mathrm{Op}_{\mathrm{z}}$ bond in the mono- $\mu$-oxo and the $\mu$-oxo/ $\mu$-hydroxo complexes.

Figures 10a and S6a display the large energy splitting of the mononuclear $\mathrm{Fe}^{\mathrm{IV}}=\mathrm{O} d-\pi^{*}$ orbitals. This is due to the large amount of oxo $p_{x, y} \pi$ character in the $d(x z)$ and $d(y z)$ orbitals with none in the $\mathrm{d}(\mathrm{xy})$ orbital. Note the mononuclear $\mathrm{Fe}^{\mathrm{IV}} \mathrm{d}(\mathrm{xz})$ and $\mathrm{d}(\mathrm{yz})$ orbitals lie close in energy due to the close $C_{4 v}$ symmetry resulting in similar oxo $\pi$ character. However, the $\mathrm{d}(\mathrm{xz})$ and $\mathrm{d}(\mathrm{yz})$ $\mathrm{d}-\pi^{*}$ splitting greatly increases and their average energy decreases in the binuclear mono- $\mu$ oxo $\mathrm{Fe}^{\mathrm{IV}}$ structure. This is primarily due to the sharing of oxo character within the $\mathrm{Fe}^{\mathrm{III}}-\mathrm{O}-$ $\mathrm{Fe}^{\mathrm{IV}}$ unit, which elongates $\mathrm{Fe}^{\mathrm{IV}}-\mathrm{O}_{\mathrm{oxo}}$ bond and causes both the $\mathrm{d}(\mathrm{xz})$ and $\mathrm{d}(\mathrm{yz})$ to lower in energy. Furthermore, while bending in the xz-plane has little effect on the energy of the d(yz) orbital, the $\mathrm{d}(\mathrm{xz})$ orbital loses $\pi$ overlap, but gains $\sigma$ overlap from the $\mathrm{Op}_{\mathrm{x}}$ orbital. This causes an energy stabilization of the $\mathrm{d}(\mathrm{xz})$ orbital, while the $\mathrm{d}(\mathrm{yz})$ orbital lowers in energy and results in a larger splitting between the two d-orbitals. The $\mathrm{Fe}^{\mathrm{IV}} \mathrm{d}\left(\mathrm{x}^{2}-\mathrm{y}^{2}\right)$ orbital in the mono- $\mu$-oxo structure has no oxo overlap and thus no energy change. The $\mu$-oxo/ $\mu$-hydroxo structure displays a somewhat smaller total energy splitting within the $\mathrm{Fe}^{\mathrm{IV}} \mathrm{d}-\pi^{*}$ manifold, which results from the added interaction between the hydroxo $\pi$ and the $d\left(x^{2}-y^{2}\right)$ orbital. This is due to a 
butterfly distortion of the $\left[\mathrm{Fe}^{\mathrm{III}}(\mu-\mathrm{O})(\mu-\mathrm{OH}) \mathrm{Fe}^{\mathrm{IV}}\right]$ unit, which offsets the oxo $\mathrm{p}_{\mathrm{x}}$ orbital and introduces some oxo character into the $\mathrm{d}\left(\mathrm{x}^{2}-\mathrm{y}^{2}\right)$ orbital, as shown in Figure S6c. The most dramatic energy change occurs within the bis- $\mu$-oxo $\mathrm{Fe}^{\mathrm{IV}} \mathrm{d}-\pi^{*}$ orbitals (Figure 10d and Table 2 and 3). In the bis- $\mu$-oxo case, there is less mixing of the $\mathrm{Fe}^{\mathrm{IV}}$ d-orbitals with the $\mathrm{Fe}^{\mathrm{III}}$ relative to the previous structures and the combined oxo character in the $\mathrm{Fe}^{\mathrm{IV}}$ increases, which increases the overall d- $\pi^{*}$ energy. More importantly, the $C_{2 v}$ symmetry of the bis- $\mu$-oxo complex provides similar oxo- $\pi$ contributions to all three $\mathrm{d}-\pi^{*}$ orbitals (from Table 2 , the percent oxo character in each of the d- $\pi^{*}$ orbitals ranges from 26,20 and 23 in the bis- $\mu$-oxo structure to 21,20 and 0 in the mono- $\mu$-oxo structure), resulting in similar $\mathrm{d}-\pi^{*}$ energies and thus a much smaller splitting within the bis- $\mu$-oxo $\mathrm{Fe}^{\mathrm{IV}} \mathrm{d}-\pi^{*}$ manifold, relative to the mono- $\mu$-oxo and $\mu$ oxo/ $\mu$-hydroxo bridged structures.

\subsection{TD-DFT: Spectral Assignments}

Time-Dependent Density Functional Theory (TD-DFT) provided a quantitative prediction of transition energies and intensities, which was applied to all three proposed intermediate $\mathrm{X}$ models, and the results for the $\mathrm{Fe}^{\mathrm{IV}}$ ligand field transitions are summarized in Figure 11 and Table 4. Slater and some $\triangle \mathrm{SCF}$ transition state energies, which converged to the spectral excited states, were also calculated for the three binuclear structures (Table 5) and provided energies similar to the TD-DFT results. The TD-DFT transition energies and intensities of the three possible $\mathrm{X}$ models were correlated to the experimental data of intermediate $\mathrm{X}$.

The TD-DFT Fe ${ }^{I V}$ d-d transitions originate from the promotion of an electron from one of the four $\beta$-occupied $\mathrm{Fe}^{\mathrm{IV}}$ d-orbitals to the $\beta$-unoccupied $\mathrm{Fe}^{\mathrm{IV}}$ d-orbital in Figures 7 - 9. Figure 11 displays the TD-DFT calculated $\mathrm{Fe}^{\mathrm{IV}} \mathrm{d}-\mathrm{d}$ transitions in blue for each structure and an overlay of the WT intermediate $\mathrm{X} \mathrm{Fe}{ }^{\mathrm{IV}} \mathrm{d}$-d transitions in red as identified from RFQ-absorption and MCD spectra, in Figures 3 and 4 . The results from the excited state analysis were consistent with the ground state splittings described above.

In general, the experimental and calculated spectra can be divided into two energy regions. The lower energy region, $<15000 \mathrm{~cm}^{-1}$, contained a single spin-allowed $\mathrm{Fe}^{\mathrm{IV}} \mathrm{d}$-d transition in all three calculated structures near $12000 \mathrm{~cm}^{-1}$, which was attributed to the strong oxo axial ligand field and the relatively weak equatorial ligand field of the mono- $\mu$-oxo and $\mu$-oxo $/ \mu$ hydroxo models and the weak axial/strong equatorial ligand field of the bis- $\mu$-oxo model that significantly split the $d-\sigma^{*}$ orbitals and the transition energy between these orbitals. This d-d transition (the $\mathrm{Fe}^{\mathrm{IV}} \mathrm{d}-\sigma^{*} \rightarrow \mathrm{d}-\sigma^{*}$ Jahn-Teller transition) was not observed in the experimental absorption or MCD data of the WT and both variants, which could reflect weak absorption and very low MCD intensity as it is well separated from the CT transitions and will not mix by spin-orbit coupling, which is required for low temperature MCD intensity. Also note that related bis- $\mu$-oxo and mono- $\mu$-oxo Mn dimers display $\mathrm{Mn}^{\mathrm{III}}\left(\right.$ high-spin $\left.\mathrm{d}^{4}, S_{\text {tot }}=2\right) \mathrm{d}$ - $\sigma^{*} \rightarrow \mathrm{d}$ $\sigma^{*}$ Jahn-Teller transitions at 11000 and $14500 \mathrm{~cm}^{-1}$ respectively, as determined by absorption, $\mathrm{CD}$ and MCD spectroscopies, ${ }^{78,79}$ which are close to the calculated $\mathrm{Fe}^{\mathrm{IV}} \mathrm{d}-\sigma^{*}$ splitting of 12 $000 \mathrm{~cm}^{-1}$ for all three model structures studied here.

Three spin-allowed $\mathrm{Fe}^{\mathrm{IV}} \mathrm{d}$-d transitions are observed in the higher energy region, $>15000$ $\mathrm{cm}^{-1}$ for both experimental and calculated spectra, and they exhibit an energy trend consistent with the ground state analysis. While electronic relaxation effects can be significant, in this case,s they were small. The ground state DFT calculations showed that the bis- $\mu$-oxo $\mathrm{Fe}^{\mathrm{IV}} \mathrm{d}$ $\pi^{*} \beta$-occupied orbitals were relatively close in energy (split by $\sim 2300 \mathrm{~cm}^{-1}$ ), whereas the mono$\mu$-oxo $\mathrm{Fe}^{\mathrm{IV}} \mathrm{d}-\pi^{*} \beta$-occupied orbitals were further split in energy $\left(\sim 8100 \mathrm{~cm}^{-1}\right)$, with the $\mu$-oxo/ $\mu$-hydroxo in-between the two $\left(\sim 3500 \mathrm{~cm}^{-1}\right)$, (Figures $\left.7-10\right)$. This same trend was displayed in the TD-DFT calculations (Figure 11 and Table 4). These three d-d transitions are thus assigned as $\mathrm{Fe}^{\mathrm{IV}} \mathrm{d}-\pi^{*} \rightarrow \mathrm{d}-\sigma^{*}$ transitions, all originating from the $\mathrm{d}-\pi^{*}$ manifold. The calculated bis- $\mu$-oxo structure displayed three $\mathrm{d}-\pi^{*} \rightarrow \mathrm{d}-\sigma^{*} \mathrm{Fe}^{\mathrm{IV}} \mathrm{d}-\mathrm{d}$ transitions all within an 
$1800 \mathrm{~cm}^{-1}$ region (at 17500,18660 and $19280 \mathrm{~cm}^{-1}$ ). The calculated mono- $\mu$-oxo structure displayed its three $\mathrm{d}-\pi^{*} \rightarrow \mathrm{d}-\sigma^{*} \mathrm{Fe}^{\mathrm{IV}} \mathrm{d}$-d transitions over a $7500 \mathrm{~cm}^{-1}$ region (at 18020,21 400 and $\left.25560 \mathrm{~cm}^{-1}\right)$. The $\mu$-oxo/ $\mu$-hydroxo structure displayed $\mathrm{d}-\pi^{*} \rightarrow \mathrm{d}-\sigma^{*} \mathrm{Fe}^{\mathrm{IV}} \mathrm{d}$-d transitions over a range of $3800 \mathrm{~cm}^{-1}$ (at 17900,19510 and $21730 \mathrm{~cm}^{-1}$ ). Importantly, the experimental RFQ-MCD determined $\mathrm{Fe}^{\mathrm{IV}} \mathrm{d}$-d transitions for WT intermediate $\mathrm{X}$ were all within a $4600 \mathrm{~cm}^{-1}$ region (at 17630,20080 and $22260 \mathrm{~cm}^{-1}$ ).

The $\mathrm{Fe}^{\mathrm{IV}} \mathrm{d}$-d transition assignment is a crucial step in the correlation of the computational models to the experimental data, and our assignments differ from those presented by Noodleman and coworkers. ${ }^{53}$ In the assignment presented here, the spectra are divided into two energy regions, the lower energy region containing the $\mathrm{Fe}^{\mathrm{IV}}$ Jahn-Teller $\mathrm{d}-\sigma^{*} \rightarrow \mathrm{d}-\sigma^{*}$ transition, not observed experimentally, and the higher energy region containing the three $\mathrm{Fe}^{\mathrm{IV}} \mathrm{d}-\pi^{*} \rightarrow \mathrm{d}-\sigma^{*}$ transitions. Furthermore, the experimental $\mathrm{d}-\pi^{*}$ splittings observed have the best correlation to the $\mathrm{d}-\pi^{*}$ splittings of the calculated $\mu$-oxo/ $\mu$-hydroxo model.

In addition to the calculated energies, the TD-DFT results provide oscillator strength information, which can help identify transitions as well as correlate to the experimental data on intermediate $\mathrm{X}$. While the experimental RFQ-absorption and MCD spectra did not display a low energy $\mathrm{Fe}^{\mathrm{IV}} \mathrm{d}-\sigma^{*} \rightarrow \mathrm{d}-\sigma^{*}$ Jahn-Teller transition at $<15000 \mathrm{~cm}^{-1}$, the spectra did display three reasonably intense $\mathrm{Fe}^{\mathrm{IV}} \mathrm{d}-\pi^{*} \rightarrow \mathrm{d}-\sigma^{*}$ transitions in the region $>15000 \mathrm{~cm}^{-1}$. Also, while MCD is important for identifying transitions, the TD-DFT oscillator strengths should be correlated to the absorption intensities. However, the experimental absorption intensities of WT intermediate X, as shown in Figure 3A and indicated by the red lines in Figure 11, are not well resolved and hence the intensities given are not a unique fit. Nevertheless, MCD still has the resolving power to identify and assign bands and give their quantitative energies; the experimental absorption intensities (Figure 11, red) are a reasonable estimate and follow the absorption spectrum for WT intermediate X (Figure 3A).

It should also be noted that there were many low energy MMCT (metal to metal charge transfer) transitions in the TD-DFT calculations, see Table S4 in Supplementary Information. These transitions are not observed experimentally and would not contribute to the MCD intensity, as MMCT are unidirectional while MCD requires two perpendicular transition dipole moments. Thus, these transitions are not displayed in Figure 11.88

The TD-DFT results displayed some agreement with the intensities of the higher energy $\mathrm{Fe}^{\mathrm{IV}} \mathrm{d}-\pi^{*} \rightarrow \mathrm{d}-\sigma^{*}$ transitions. However, the mono- $\mu$-oxo and $\mu$-oxo/ $\mu$-hydroxo structures displayed unreasonably large low energy $\mathrm{Fe}^{\mathrm{IV}} \mathrm{d}-\sigma^{*} \rightarrow \mathrm{d}-\sigma^{*}$ Jahn-Teller transition TD-DFT intensities due to borrowing from nearby intense MMCT transitions that strongly contribute to the calculated absorption intensities. Therefore, we turn to group theory to gain insight into the $\mathrm{Fe}^{\mathrm{IV}} \mathrm{d}$-d transition intensities for the different possible structures for X. Figure 12 gives the predicted intensities for the mono- $\mu$-oxo and $\mu$-oxo/ $\mu$-hydroxo structures. Both structures follow a similar dissent in symmetry starting from a mononuclear high-spin $\mathrm{Fe}^{\mathrm{IV}}$ in $O_{h}$ symmetry that is lowered to $C_{4 v}$ due to the strong $\mathrm{Fe}^{\mathrm{IV}}$ - oxo bond (in an oxo monomer or a linear $\mathrm{Fe}^{\mathrm{IV}}-\mathrm{O}-\mathrm{Fe}^{\mathrm{III}}$ dimer). In $C_{4 v}$ symmetry only one $\mathrm{Fe}^{\mathrm{IV}}$ d-d transition is orbitally allowed, ${ }^{5} \mathrm{~A}_{1} \rightarrow{ }^{5} \mathrm{E}\left(\mathrm{e} \rightarrow \mathrm{a}_{1}\right)$, and should have significant absorption intensity. Upon bending of the $\mathrm{Fe}^{\mathrm{IV}}-\mathrm{O}-\mathrm{Fe}^{\mathrm{III}}$ dimer, the effective symmetry is lowered to $C_{S}$ and all four spin-allowed d-d transitions become orbitally allowed, however the most intense transitions will arise from the ${ }^{5} \mathrm{~A}_{1} \rightarrow{ }^{5} \mathrm{E}\left(\mathrm{e} \rightarrow \mathrm{a}_{1}\right) C_{4 v}$ parent transition. Thus, group theory predicts the mono- $\mu$-oxo and the $\mu$-oxo/ $\mu$-hydroxo cases will display four orbital- and spin-allowed d-d transitions, with the two inner $\mathrm{d}-\pi^{*}$ transitions being more intense (Figure 12).

The bis- $\mu$-oxo case is given in Figure 13, with the two cis oxo ligands that lower the $\mathrm{Fe}$ IV symmetry to $C_{2 v}$ and the d-orbitals split accordingly. Group theory predicts three orbitally 
allowed transitions in the bis- $\mu$-oxo structure, one $\mathrm{d}-\sigma^{*}$ and two $\mathrm{d}-\pi^{*} \rightarrow \mathrm{d}-\sigma^{*}$. If the symmetry is further lowered, the fourth spin-allowed $\mathrm{d}-\pi^{*}$ transition can borrow intensity, yielding three moderately intense $\mathrm{d}-\mathrm{d}$ transitions with a weaker transition in the middle.

While the lowest energy Jahn-Teller transition, $\mathrm{Fe}^{\mathrm{IV}} \mathrm{d}-\sigma^{*} \rightarrow \mathrm{d}-\sigma^{*}$, was not experimentally observed, group theory predicts the lowest energy Jahn-Teller transition, $\mathrm{Fe}^{\mathrm{IV}} \mathrm{d}-\sigma^{*} \rightarrow \mathrm{d}-\sigma^{*}$, to have significant intensity in the bis- $\mu$-oxo structure, but little intensity in the mono- $\mu$-oxo and $\mu$-oxo/ $\mu$-hydroxo structures (Figures 11 and 12 ). Thus, the group theory intensity prediction is also consistent with the $\mu$-oxo/ $\mu$-hydroxo but not the bis- $\mu$-oxo structure.

In summary, the energy and intensity comparison of the TD-DFT calculated $\mathrm{Fe}^{\mathrm{IV}} \mathrm{d}$-d transitions (blue) with the RFQ-absorption and MCD spectra of WT X (red) in Figure 11 and Tables 1 and 4, best correlate with and strongly support the $\mu$-oxo/ $\mu$-hydroxo structure for intermediate $X$. The Slater transition energies in Table 5 are consistent with the TD-DFT results and also agree with the $\mu$-oxo/ $\mu$-hydroxo model. This is further supported by the structural perturbations as described below.

\section{Structural Perturbations of $X$}

The variations of the $\mathrm{Fe}^{\mathrm{IV}} \mathrm{d}-\mathrm{d}$ transitions in the RFQ-MCD spectra of Figure 4 from the WT and the two variants further support the $\mu$-oxo/ $\mu$-hydroxo model and indicate that the Fe remote to $\mathrm{Y} 122$ is the $\mathrm{Fe}^{\mathrm{IV}}$ center. Previous Mössbauer ${ }^{41}$ and $\mathrm{MCD}^{26}$ studies also suggested that the $\mathrm{Fe}^{\mathrm{IV}}$ is remote to $\mathrm{Y} 122$.

The calculated TD-DFT and Slater transition energy separation between the two lowest energy $\mathrm{Fe}^{\mathrm{IV}} \mathrm{d}-\mathrm{d}$ transitions (the Jahn-Teller $\mathrm{d}-\sigma^{*} \rightarrow \mathrm{d}-\sigma^{*}$ transition and the lowest $\mathrm{d}-\pi^{*} \rightarrow \mathrm{d}-\sigma^{*}$ transition) was $\sim 6000 \mathrm{~cm}^{-1}$ for all three structures. This large energy separation does not correlate to the WT or any variant $\mathrm{Fe}^{\mathrm{IV}}$ band 1 - band 2 energy separation and further substantiates that the three observed RFQ-MCD transitions all originate from the $\mathrm{Fe}^{\mathrm{IV}} \mathrm{d}-\pi^{*}$ manifold. Furthermore, Figure 4 shows that all three $\mathrm{Fe}^{\mathrm{IV}} \mathrm{d}$-d transitions shift in unison, which would not be possible if band 1 in the RFQ-MCD spectra was assigned as the Jahn-Teller transition. As the $d-\sigma^{*}-d-\sigma^{*}$ splitting increases, the $d-\pi^{*}-d-\pi^{*}$ splitting would also increase. Thus, if band 1 were the $\mathrm{d}-\sigma^{*}$ transition and band 2 were the lowest energy $\mathrm{d}-\pi^{*}$ transition, the splitting between band 1 and 2 would decrease, which is not observed between the WT and variant RFQ-MCD spectra. Therefore, the three identified spin-allowed $\mathrm{Fe}^{\mathrm{IV}} \mathrm{d}$-d transitions in the RFQ-MCD spectra of X for WT, and the W48A and Y122F/Y356F variants directly reflect the splitting of the $\mathrm{Fe}^{\mathrm{IV}} \mathrm{d}-\pi^{*}$ manifold. The total $\mathrm{Fe}^{\mathrm{IV}} \mathrm{d}-\pi^{*}$ manifold splitting is $4630 \mathrm{~cm}^{-1}$ for the WT-X (bands 1-3 at 17 630, 20080 and $22260 \mathrm{~cm}^{-1}$ ), whereas the manifold decreases to $2980 \mathrm{~cm}^{-1}$ in the W48A variant $\left(19680,21590\right.$ and $\left.22660 \mathrm{~cm}^{-1}\right)$ and increases to 5400 $\mathrm{cm}^{-1}$ in the Y122F/Y356F variant $\left(16700,19460\right.$ and $\left.22100 \mathrm{~cm}^{-1}\right)$. The TD-DFT calculated energy separation of the $\mathrm{d}-\pi^{*}$ manifold is $\sim 7400 \mathrm{~cm}^{-1}$ for the mono- $\mu$-oxo structure, $\sim 3800$ $\mathrm{cm}^{-1}$ for the $\mu$-oxo $/ \mu$-hydroxo structure and $\sim 1900 \mathrm{~cm}^{-1}$ for the bis- $\mu$-oxo structure. In addition, while the W48A variant exhibited the smallest splitting of the $\mathrm{Fe}^{\mathrm{IV}} \mathrm{d}-\pi^{*}$ manifold, it was still significantly larger than the splitting calculated for the bis- $\mu$-oxo model.

These large changes in the $\mathrm{Fe}^{\mathrm{IV}} \mathrm{d}-\pi^{*}$ manifold can be correlated to perturbations of $\mathrm{X}$ through structural changes that occur in response to the substitutions. Figure 14 displays the proposed structural perturbations of $\mathrm{X}$ that correlate with the $\mathrm{Fe}^{\mathrm{IV}} \mathrm{d}-\pi^{*}$ manifold splitting for the WT and two variants. The proposed structure for WT intermediate X is shown in Figure 14B with the $\mu$-oxo/ $\mu$-hydroxo core structure with the $\mathrm{Fe}^{\mathrm{III}}$ coordinated by a terminal hydroxide and a monodentate D84 that H-bonds to the -OH of Y122. However, in the proposed structure for Y122F/Y356F - X (Figure 14A), the replacement of tyrosine with phenylalanine disrupts this H-bonding network, which would result in the D84 carboxylate and the terminal hydroxide donating more charge to the $\mathrm{Fe}^{\mathrm{III}}$. This in turn would weaken the $\mathrm{Fe}^{\mathrm{III}}-\mathrm{O}_{\text {oxo }}$ bond and thus 
strengthen the $\mathrm{O}_{\mathrm{oxo}}-\mathrm{Fe}^{\mathrm{IV}}$ bonding, which would result in a larger splitting of the $\mathrm{Fe}^{\mathrm{IV}} \mathrm{d}-\pi^{*}$ manifold, as observed in the MCD spectrum in Figure 4B. It is important to note that if the Fe closest to $\mathrm{Y} 122$ were the $\mathrm{Fe}^{\mathrm{IV}}$, then the predicted trend would be opposite to what is experimentally observed.

The W48A variant forms $\mathrm{X}$ by oxidizing Y122 to Y122•, which would also disrupt the Hbonding network (Figure 14C), but by a different mechanism than in the Y122F/Y356F variant. In this case, the proton from Y122-OH could be transferred in a PCET process to either the terminal hydroxide or to the D84 carboxylate and result in the donation of less charge to the $\mathrm{Fe}^{\mathrm{III}}$ by these ligands. This change would, in turn, strengthen the $\mathrm{Fe}^{\mathrm{III}}-\mathrm{O}_{\text {oxo }}$ bond and weaken the $\mathrm{O}_{\mathrm{oxo}}-\mathrm{Fe}^{\mathrm{IV}}$ bonding, which would result in a smaller splitting of the $\mathrm{Fe}^{\mathrm{IV}} \mathrm{d}-\pi^{*}$ manifold, as observed in the MCD spectrum in Figure 4C. Again, the opposite trend would be observed if the $\mathrm{Fe}^{\mathrm{IV}}$ were proximal to the $\mathrm{Y} 122$.

The structural and related spectroscopic perturbations associated with these substitutions also help in the evaluation and exclusion of the possibility of a bis- $\mu$-oxo structure for intermediate $\mathrm{X}$. The bis- $\mu$-oxo structure is relatively symmetric and thus would maintain a reasonably small splitting of its $\mathrm{Fe}^{\mathrm{IV}} \mathrm{d}-\pi^{*}$ manifold. Previous studies on a related bis- $\mu$-oxo $\mathrm{Mn}^{\mathrm{III}}-\mathrm{Mn}^{\mathrm{IV}}$ dimer suggest that core bending or butterfly distortion reduces Mn-oxo overlap as observed in its absorption spectrum. ${ }^{79}$ Therefore, an increased butterfly distortion of the $\mathrm{Fe}^{\mathrm{III}}-(\mu-\mathrm{O})_{2}-\mathrm{Fe}^{\mathrm{IV}}$ bis- $\mu$-oxo core would decrease the $\mathrm{Fe}$ - oxo overlap, which would further decrease the splitting of the $\mathrm{d}-\pi^{*}$ manifold, making correlation to the $\mathrm{WT} \mathrm{X} \mathrm{Fe} \mathrm{IV}^{\mathrm{IV}} \mathrm{d}-\mathrm{d}$ transitions worse and explanation of the larger $\mathrm{d}-\pi^{*}$ splitting in the $\mathrm{Y} 122 \mathrm{~F} / \mathrm{Y} 356 \mathrm{~F} \mathrm{X}$ variant even more problematic.

Thus, from these correlations, it appears that the substitutions of $\mathrm{Y} 122 \mathrm{~F} / \mathrm{Y} 356 \mathrm{~F}$ and W48A directly perturb the $\mathrm{Fe}^{\mathrm{III}}$ site of $\mathrm{X}$, which indirectly perturbs the $\mathrm{Fe}^{\mathrm{IV}}$ through the oxo bond. This analysis supports the Mössbauer and MCD results that the $\mathrm{Fe}^{\mathrm{IV}}$ is the remote iron center located distal to Y122 and further supports the $\mu$-oxo/ $\mu$-hydroxo core structure for intermediate $\mathrm{X}$. It also raises important mechanistic implications for the geometric and electronic structure of $\mathrm{X}$, as discussed below.

\section{Discussion}

Through the correlation of EPR, absorption, MCD and VTVH MCD spectroscopies with DFT and TD-DFT calculations, we have determined that the $\mu$-oxo/ $\mu$-hydroxo core structure $\left[\mathrm{Fe}^{\mathrm{III}}(\mu-\mathrm{O})(\mu-\mathrm{OH}) \mathrm{Fe}^{\mathrm{IV}}\right]$ best correlates to the experimental data for the electronic and geometric structure of X. The variants perturb the Fe closest to the Y122, in a manner which is opposite to what is observed in the spectral changes of the $\mathrm{Fe}^{\mathrm{IV}}$. This supports a structure where the $\mathrm{Fe}^{\mathrm{IV}}$ is remote to $\mathrm{Y} 122$ and is perturbed through the mono- $\mu$-oxo bridge. The geometric and electronic structure characterization of intermediate $\mathrm{X}$ provides a greater understanding of its reactivity in RNR and further insight into the factors that tune its $\mathrm{O}_{2}$ reactivity relative to the other binuclear non-heme iron enzymes.

The $\mathrm{R} 2$ binuclear non-heme ferrous site reacts with $\mathrm{O}_{2}$ to ultimately generate a radical on $\mathrm{Y} 122$ through intermediate $\mathrm{X}$. Scheme 2 presents two possible mechanistic pathways by which the previously established $c i s-\mu 1,2$-peroxo diferric structure ${ }^{23,36}$ could convert to intermediate $\mathrm{X}$. These two pathways both result in cleavage of the $\mathrm{O}-\mathrm{O}$ bond; however, the upper pathway is triggered by the protonation of the peroxide. Past studies on the $c i s-\mu 1,2$-peroxo diferric structure show it is activated for protonation. ${ }^{23,89}$ Once protonated, the hydroperoxo would raise the potential of the complex and lower the energy of the peroxo $\sigma^{*}$ orbital, activating it to oxidize one electron from the remote $\mathrm{Fe}^{\mathrm{III}}$ and the other from the tryptophan residue (W48 in $E$. coli $\mathrm{R} 2$ ) to promote the two electron reduction and cleavage of the $\mathrm{O}-\mathrm{O}$ bond, thus forming a $\mu$-oxo $/ \mu$-hydroxo $\left[\mathrm{Fe}^{\mathrm{III}}(\mu-\mathrm{O})(\mu-\mathrm{OH}) \mathrm{Fe}^{\mathrm{IV}}\right]$ core structure for intermediate $\mathrm{X}$. If the peroxo 
were not protonated, it is possible that it could rearrange to a $\mu-\eta^{2}: \eta^{2}$ structure and undergo homolysis of the $\mathrm{O}-\mathrm{O}$ bond to form the bis- $\mu$-oxo structure. Our experimental results strongly support a $\mu$-oxo/ $\mu$-hydroxo core structure with the protonation step activating $\mathrm{O}-\mathrm{O}$ bond cleavage.

Our data and structural assignment of $\mathrm{X}$ are in reasonable agreement with previous ${ }^{1,2} \mathrm{H}$ and ${ }^{17} \mathrm{O}$ ENDOR studies of $\mathrm{X}$ by the Hoffman and Stubbe groups that display two different ${ }^{17} \mathrm{O}$ peaks from ${ }^{17} \mathrm{O}_{2}$ (and a a ${ }^{1,2} \mathrm{H}$ peak from ${ }^{1,2} \mathrm{H}_{2} \mathrm{O}$ ) that have been assigned to a single oxo bridge and a terminal hydroxo on the Fe ${ }^{\mathrm{III}} .39,40$ However, our RFQ-MCD data are more consistent with a bridging rather than a terminal hydroxo, which would also be more consistent with the EXAFS Fe-Fe distance. ${ }^{37}$ Consistent with our MCD results, the ENDOR data do not support a bis- $\mu$-oxo "diamond core" structure for X.

Recently, Noodleman and coworkers proposed a bis- $\mu$-oxo "diamond core" structure for X based on the correlation of $\mathrm{Fe}^{\mathrm{IV}} \mathrm{d}$-d transitions calculated from $\triangle \mathrm{SCF}$ and Slater transition state methods of four possible models with a truncated binuclear iron active site and the experimentally determined $\mathrm{Fe}^{\mathrm{IV}} \mathrm{d}$-d transitions from our RFQ-MCD spectrum of $\mathrm{X}$ in the Y122F/Y356F variant. ${ }^{53}$ This variant displays three $\mathrm{Fe}^{\mathrm{IV}}$ spin-allowed d-d transitions with the largest d-d energy splittings of the three investigated species of intermediate X. A comparison of Noodleman's Slater transitions to our TD-DFT and Slater transitions show similar energy splittings for the mono- $\mu$-oxo, $\mu$-oxo/ $\mu$-hydroxo and bis- $\mu$-oxo structures, despite ligand differences between their structures relative to those used here (Figures 7-9). They correlate the lowest energy Jahn-Teller $d-\sigma^{*} \rightarrow d-\sigma^{*}$ transition to band 1 in our MCD spectrum. However, all three observed MCD bands shift in unison from the WT transitions to the perturbed W48A and Y122F/Y356F variant transitions. Since the Jahn-Teller transition would shift in a manner opposite to the $\mathrm{d}-\pi^{*}$ manifold, this means that all three experimentally observed $\mathrm{Fe}^{\mathrm{IV}} \mathrm{d}$-d transitions must arise from the $\mathrm{d}-\pi^{*}$ manifold. Alternatively, the energy differences for the higher energy $\mathrm{d}-\pi^{*}$ transitions of their $\mu$-oxo/ $\mu$-hydroxo and mono- $\mu$-oxo models in reference 53 correlate much closer (than the d- $\pi^{*}$ transitions of their bis- $\mu$-oxo structure) to the RFQ-MCD spectrum of WT intermediate X.

The electronic and geometric structures of $\mathrm{X}$ in Figures 15 and 16 respectively, are well tuned to oxidize Y122 by one electron, likely via a proton-coupled electron transfer (PCET) process. Figure 16 shows the H-bonding interaction between D84 and Y122-OH, which would provide a superexchange pathway to the proximal Fe ${ }^{\mathrm{III}}$. The electron would then transfer to the lowest energy unoccupied orbital on the $\mathrm{Fe}^{\mathrm{III}}$. The mono- $\mu$-oxo bridge would then play an important role in electron transfer from the $\mathrm{Fe}^{\mathrm{III}}$ to the remote $\mathrm{Fe}^{\mathrm{IV}}$. Figure 15B shows the LUMO ( $\beta$-124) of the $\mu$-oxo/ $\mu$-hydroxo core structure $\left[\mathrm{Fe}^{\mathrm{III}}(\mu-\mathrm{O})(\mu-\mathrm{OH}) \mathrm{Fe}^{\mathrm{IV}}\right]$, which displays a good $\pi / \sigma$ superexchange pathway between the $\mathrm{Fe}^{\mathrm{III}} \mathrm{d}(\mathrm{xz})$ and the $\mathrm{Fe}^{\mathrm{IV}}(\mathrm{dz} 2)$. This bent $\mu$-oxo superexchange pathway provides an efficient and favorable path for the electron transfer from Y122 through the $\mathrm{Fe}^{\mathrm{III}}$ to the remote $\mathrm{Fe}^{\mathrm{IV}}$, as shown in Figure 16.

In addition, there would be fundamental reactivity differences between the $\mu$-oxo $/ \mu$-hydroxo and bis- $\mu$-oxo structures in $\mathrm{H}$ atom abstraction from Y122. In contrast to the $\mu$-oxo/ $\mu$-hydroxo, the bis- $\mu$-oxo structure contains an extremely poor ET pathway within the $\mathrm{Fe}^{\mathrm{III}}(\mu-\mathrm{O})_{2} \mathrm{Fe}^{\mathrm{IV}}$ unit to transfer an electron from $\mathrm{Y} 122$ to the remote $\mathrm{Fe}^{\mathrm{IV}}$, as shown in Figure 15A. In contrast to the $\mu$-oxo/ $\mu$-hydroxo structure, which has a highly delocalized orbital pathway between the $\mathrm{Fe}^{\mathrm{III}}$ and $\mathrm{Fe}^{\mathrm{IV}}$, the bis- $\mu$-oxo structure localizes the LUMO on the remote $\mathrm{Fe}^{\mathrm{IV}}$ and provides a poor superexchange pathway betweenY122 near the $\mathrm{Fe}^{\mathrm{III}}$ and the remote $\mathrm{Fe}^{\mathrm{IV}}$.

It is interesting to compare the reactivity of $\mathrm{R} 2$ to that of another binuclear non-heme iron protein, hemerythrin. In hemerythrin, $\mathrm{O}_{2}$ reversibly binds to one $\mathrm{Fe}$, yet there is ET from the second Fe through a bent mono- $\mu$-oxo bridge. ${ }^{4,5}$ Again, it has been shown that the $\pi / \sigma$ 
superexchange pathway associated with the bent oxo bridge allows ET to the remote Fe. The bent $\mu$-oxo bridge also plays a dominant role in the exchange coupling of bent ferric oxo dimer sites in both proteins and model complexes, and these studies connect the $\pi / \sigma$ exchange coupling in the homo dimers to the superexchange pathway for ET through the bent $\mu$-oxo bridge. 75,77

In summary, the spectroscopic and computational studies presented here support a $\mu$-oxo/ $\mu$ hydroxo $\left[\mathrm{Fe}^{\mathrm{III}}(\mu-\mathrm{O})(\mu-\mathrm{OH}) \mathrm{Fe}^{\mathrm{IV}}\right]$ core structure for intermediate $\mathrm{X}$, and that this core structure is well tuned to provide an efficient and favorable $\pi / \sigma$ superexchange pathway for PCET from Y122 to the remote $\mathrm{Fe}^{\mathrm{IV}}$ to generate the catalytically essential tyrosyl radical in class I RNR.

\section{Supplementary Material}

Refer to Web version on PubMed Central for supplementary material.

\section{Acknowledgements}

We thank Brian Hoffman for his helpful ENDOR discussions of intermediate X. We thank financial support by the NSF Molecular Biophysics Program (MCB-342807 to E.I.S.), NIH (GM-55365 to J.M.B., Jr.) and NIH R.L.

Kirschstein NRSA Fellowship (GM-70292 to M.D.C).

\section{References}

1. Solomon EI, Brunold TC, Davis MI, Kemsley JN, Lee SK, Lehnert N, Neese F, Skulan AJ, Yang YS, Zhou J. Chem Rev 2000;100:235-349. [PubMed: 11749238]

2. Nordlund P, Eklund H. Curr Opin Struc Biol 1995;5:758-766.

3. Wallar BJ, Lipscomb JD. Chem Rev 1996;96:2625-2657. [PubMed: 11848839]

4. Brunold TC, Solomon EI. J Am Chem Soc 1999;121:8277-8287.

5. Brunold TC, Solomon EI. J Am Chem Soc 1999;121:8288-8295.

6. Merkx M, Kopp DA, Sazinsky MH, Blazyk JL, Muller J, Lippard SJ. Angew Chem Int Edit 2001;40:2782-2807.

7. Fox BG, Froland WA, Jollie DR, Lipscomb JD. Method Enzymol 1990;188:191-202.

8. Schmidt H, Heinz E. Plant Physiol 1990;94:214-220. [PubMed: 16667689]

9. Wada H, Schmidt H, Heinz E, Murata N. J Bacteriol 1993;175:544-547. [PubMed: 8419301]

10. Fox BG, Lyle KS, Rogge CE. Acc Chem Res 2004;37:421-429. [PubMed: 15260504]

11. Reichard P, Ehrenberg A. Science 1983;221:514-519. [PubMed: 6306767]

12. Nordlund P, Eklund H. J Mol Biol 1993;232:123-164. [PubMed: 8331655]

13. Stubbe J. Curr Opin Chem Biol 2003;7:183-188. [PubMed: 12714050]

14. Nordlund P, Reichard P. Annu Rev Biochem 2006;75:681-706. [PubMed: 16756507]

15. Nordlund P, Sjoberg BM, Eklund H. Nature 1990;345:593-598. [PubMed: 2190093]

16. Rosenzweig AC, Nordlund P, Takahara PM, Frederick CA, Lippard SJ. Chem Biol 1995;2:632.

17. Elango N, Radhakrishnan R, Froland WA, Wallar BJ, Earhart CA, Lipscomb JD, Ohlendorf DH. Protein Sci 1997;6:556-568. [PubMed: 9070438]

18. Bollinger JM Jr, Edmondson DE, Huynh BH, Filley J, Norton JR, Stubbe J. Science 1991;253:292298. [PubMed: 1650033]

19. Bollinger JM Jr, Tong WH, Ravi N, Huynh BH, Edmondson DE, Stubbe J. Method Enzymol 1995;258:278-303.

20. Liu KE, Valentine AM, Wang DL, Huynh BH, Edmondson DE, Salifoglou A, Lippard SJ. J Am Chem Soc 1995;117:10174-10185.

21. Lee SK, Nesheim JC, Lipscomb JD. J Biol Chem 1993;268:21569-21577. [PubMed: 8408008]

22. Broadwater JA, Ai JY, Loehr TM, Sanders-Loehr J, Fox BG. Biochemistry 1998;37:14664-14671. [PubMed: 9778341] 
23. Skulan AJ, Brunold TC, Baldwin J, Saleh L, Bollinger JM Jr, Solomon EI. J Am Chem Soc 2004;126:8842-8855. [PubMed: 15250738]

24. Stubbe J, Nocera DG, Yee CS, Chang MCY. Chem Rev 2003;103:2167-2201. [PubMed: 12797828]

25. Licht SS, Stubbe J. FASEB J 1995;9:A1320-A1320.

26. Yang YS, Baldwin J, Ley BA, Bollinger JM Jr, Solomon EI. J Am Chem Soc 2000;122:8495-8510.

27. Wei PP, Skulan AJ, Mití N, Yang YS, Saleh L, Bollinger JM Jr, Solomon EI. J Am Chem Soc 2004;126:3777-3788. [PubMed: 15038731]

28. Ravi N, Bollinger JM Jr, Huynh BH, Edmondson DE, Stubbe J. J Am Chem Soc 1994;116:80078014.

29. Bollinger JM Jr, Tong WH, Ravi N, Huynh BH, Edmondson DE, Stubbe J. J Am Chem Soc 1994;116:8024-8032.

30. Bollinger JM Jr, Tong WH, Ravi N, Huynh BH, Edmondson DE, Stubbe J. J Am Chem Soc 1994;116:8015-8023.

31. Ling JS, Sahlin M, Sjoberg BM, Loehr TM, Sanders-Loehr J. J Biol Chem 1994;269:5595-5601. [PubMed: 8119895]

32. Solomon EI. Inorg Chem 2001;40:3656-3669. [PubMed: 11442362]

33. Siegbahn PEM. Chem Phys Lett 2002;351:311-318.

34. Gherman BF, Baik MH, Lippard SJ, Friesner RA. J Am Chem Soc 2004;126:2978-2990. [PubMed: 14995216]

35. Shu LJ, Nesheim JC, Kauffmann K, Munck E, Lipscomb JD, Que L. Science 1997;275:515-518. [PubMed: 8999792]

36. Yun D, Garcia-Serres R, Chicalese BM, An YH, Huynh BH, Bollinger JM Jr. Biochemistry. 2007ASAP article

37. Riggs-Gelasco PJ, Shu LJ, Chen SX, Burdi D, Huynh BH, Que L, Stubbe J. J Am Chem Soc 1998;120:849-860.

38. Mití N, Saleh L, Schenk G, Bollinger JM Jr, Solomon EI. J Am Chem Soc 2003;125:11200-11201. [PubMed: 16220933]

39. Willems JP, Lee HI, Burdi D, Doan PE, Stubbe J, Hoffman BM. J Am Chem Soc 1997;119:98169824.

40. Burdi D, Willems JP, Riggs-Gelasco P, Antholine WE, Stubbe J, Hoffman BM. J Am Chem Soc 1998;120:12910-12919.

41. Bollinger JM Jr, Chen SX, Parkin SE, Mangravite LM, Ley BA, Edmondson DE, Huynh BH. J Am Chem Soc 1997;119:5976-5977.

42. Siegbahn PEM. Inorg Chem 1999;38:2880-2889. [PubMed: 11671034]

43. Lovell T, Li J, Noodleman L. J Biol Inorg Chem 2002;7:799-809. [PubMed: 12203016]

44. Torrent M, Vreven T, Musaev DG, Morokuma K, Farkas O, Schlegel HB. J Am Chem Soc 2002;124:192-193. [PubMed: 11782169]

45. Torrent M, Musaev DG, Basch H, Morokuma K. J Comput Chem 2002;23:59-76. [PubMed: 11913390]

46. Han WG, Lovell T, Liu TQ, Noodleman L. Inorg Chem 2003;42:2751-2758. [PubMed: 12691585]

47. Liu TQ, Lovell T, Han WG, Noodleman L. Inorg Chem 2003;42:5244-5251. [PubMed: 12924895]

48. Siegbahn PEM. Q Rev Biophys 2003;36:91-145. [PubMed: 12643044]

49. Han WG, Lovell T, Liu TQ, Noodleman L. Inorg Chem 2004;43:613-621. [PubMed: 14731023]

50. Liu TQ, Lovell T, Han WG, Noodleman L. Inorg Chem 2004;43:6858-6858.

51. Han WG, Liu TQ, Lovell T, Noodleman L. J Am Chem Soc 2005;127:15778-15790. [PubMed: 16277521]

52. Han WG, Liu TQ, Lovell T, Noodleman L. J Inorg Biochem 2006;100:771-779. [PubMed: 16504298]

53. Han WG, Liu TQ, Lovell T, Noodleman L. Inorg Chem 2006;45:8533-8542. [PubMed: 17029364]

54. Baldwin J, Krebs C, Ley BA, Edmondson DE, Huynh BH, Bollinger JM Jr. J Am Chem Soc 2000;122:12195-12206.

55. Krebs C, Chen SX, Baldwin J, Ley BA, Patel U, Edmondson DE, Huynh BH, Bollinger JM Jr. J Am Chem Soc 2000;122:12207-12219. 
56. Saleh L, Krebs C, Ley BA, Naik S, Huynh BH, Bollinger JM Jr. Biochemistry 2004;43:5953-5964. [PubMed: 15147179]

57. Saleh L, Kelch BA, Pathickal BA, Baldwin J, Ley BA, Bollinger JM Jr. Biochemistry 2004;43:59435952. [PubMed: 15147178]

58. Parkin SE, Chen SX, Ley BA, Mangravite L, Edmondson DE, Huynh BH, Bollinger JM Jr. Biochemistry 1998;37:1124-1130. [PubMed: 9454605]

59. Saleh L, Bollinger JM Jr. Biochemistry 2006;45:8823-8830. [PubMed: 16846225]

60. Solomon EI, Pavel EG, Loeb KE, Campochiaro C. Coord Chem Rev 1995;144:369-460.

61. Noodleman L, Case DA, Aizman A. J Am Chem Soc 1988;110:1001-1005.

62. Noodleman L. J Chem Phys 1981;74:5737-5743.

63. Noodleman L, Davidson ER. Chem Phys 1986;109:131-143.

64. Baerends EJ, Ellis DE, Ros P. Chem Phys 1973;2:41-51.

65. Velde GT, Baerends EJ. J Comput Phys 1992;99:84-98.

66. Vosko SH, Wilk L, Nusair M. Can J Phys 1980;58:1200-1211.

67. Becke AD. J Chem Phys 1986;84:4524-4529.

68. Perdew JP. Phys Rev B 1986;33:8822-8824.

69. Gorelsky, SI. AOMIX program, revision 6.04 (http://www.sg-chem.net/) (b) Gorelsky SI, Lever ABP. J Organomet Chem 2001;635:187-196.

70. Tenderholt, AL. PyMOlyze. Version 1.04., http://pymolyze.sourceforge.net

71. Frisch, MJ., et al. Gaussian 03. Gaussian, Inc.; Wallingford CT: 2004. Revision C.02

72. $\mathrm{J} \sim 0.1 \mathrm{~cm}^{-1}$

73. Solomon, EI.; Hanson, MA. Inorganic Electronic Structure and Spectroscopy. 1. Solomon, EI.; Lever, ABP., editors. 2. John Wiley \& Sons; New York: 1999. p. 1-129.

74. The high-spin Fe $\mathrm{e}^{\mathrm{III}} \mathrm{d}-\mathrm{d} \mathrm{LF}$ transitions are all spin-forbidden.

75. Brown CA, Remar GJ, Musselman RL, Solomon EI. Inorg Chem 1995;34:688-717.

76. Jorgensen, K. Oxidation Numbers and Oxidation States. Springer-Verlag; New York: 1969.

77. Brunold TC, Gamelin DR, Solomon EI. J Am Chem Soc 2000;122:8511-8523.

78. Brunold TC, Gamelin DR, Stemmler TL, Mandal SK, Armstrong WH, Penner-Hahn JE, Solomon EI. J Am Chem Soc 1998;120:8724-8738.

79. Gamelin DR, Kirk ML, Stemmler TL, Pal S, Armstrong WH, Penner-Hahn JE, Solomon EI. J Am Chem Soc 1994;116:2392-2399.

80. Han WG, Liu TQ, Lovell T, Noodleman L. J Comput Chem 2006;27:1292-1306. [PubMed: 16786546]

81. Stubna A, Jo DH, Costas M, Brenessel WW, Andres H, Bominaar EL, Munck E, Que L. Inorg Chem 2004;43:3067-3079. [PubMed: 15132612]

82. Hsu HF, Dong YH, Shu LJ, Young VG, Que L. J Am Chem Soc 1999;121:5230-5237.

83. Wieghardt K, Pohl K, Gebert W. Angew Chem Int Edit 1983;22:727-727.

84. Slep LD, Mijovilovich A, Meyer-Klaucke W, Weyhermuller T, Bill E, Bothe E, Neese F, Wieghardt K. J Am Chem Soc 2003;125:15554-15570. [PubMed: 14664603]

85. Rohde JU, In JH, Lim MH, Brennessel WW, Bukowski MR, Stubna A, Munck E, Nam W, Que L. Science 2003;299:1037-1039. [PubMed: 12586936]

86. Decker A, Clay MD, Solomon EI. J Inorg Biochem 2006;100:697-706. [PubMed: 16510189]

87. The high-spin $S=2$ mononuclear $\mathrm{Fe}^{\mathrm{IV}}=\mathrm{O}$ structure used here is a six-coordinate structure (as in the activated non-heme iron enzymes), consisting of two amines which model histidines, one formate which models glutamate or aspartate, one hydroxide and one water.

88. While the bis- $\mu$-oxo and $\mu$-oxo/ $\mu$-hydroxo structures displayed dominant and clear $\mathrm{Fe}^{\mathrm{IV}} \mathrm{d}$-d transitions in the TD-DFT and Slater transition state calculations, the mono- $\mu$-oxo structure had larger spinpolarization effects that complicate the assignment of specific transitions. However, analysis of the individual molecular orbitals and transitions for the mono- $\mu$-oxo structure allowed the identification of all four $\mathrm{Fe}^{\mathrm{IV}} \mathrm{d}$-d transitions. In the cases where spin-polarization had mixed an $\mathrm{Fe}^{\mathrm{IV}} \mathrm{d}$-orbital into several transitions, an average energy is given for these transitions, Table 3. 
89. Brunold TC, Tamura N, Kitajima N, Moro-oka Y, Solomon EI. J Am Chem Soc 1998;120:56745690. 


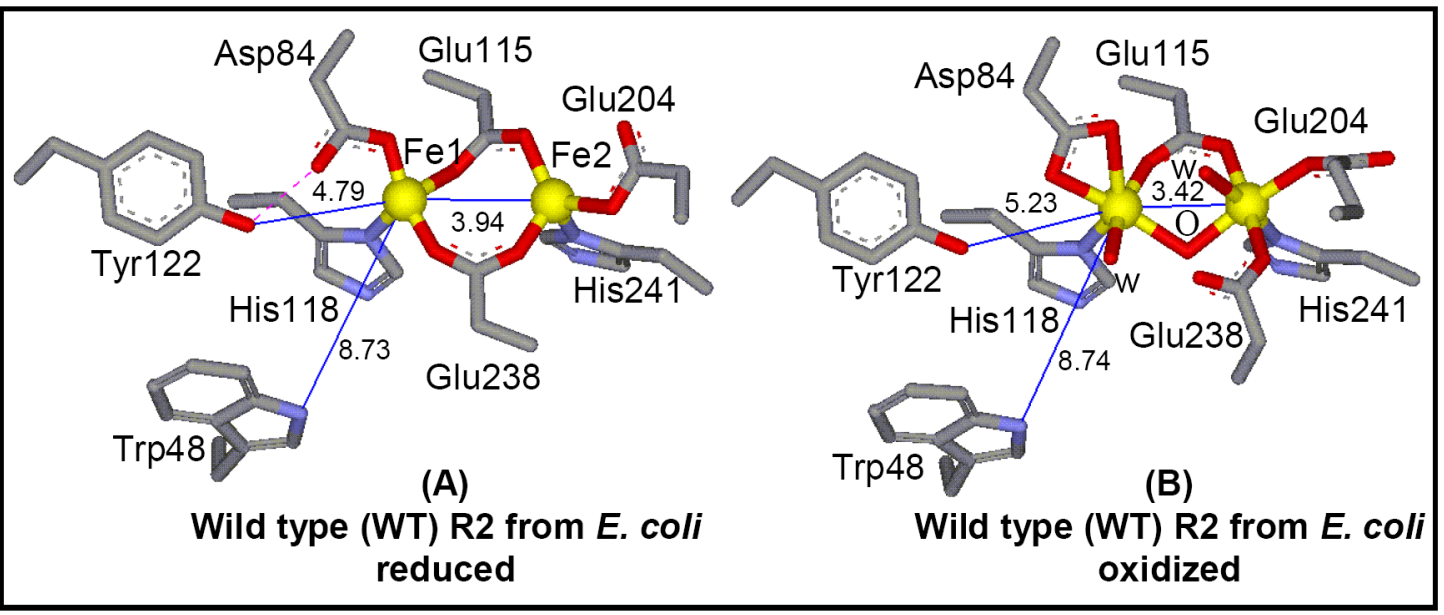

Figure 1.

Crystal structures of the (A) reduced binuclear active site of R2-WT (1XIK), and (B) oxidized binuclear active site of R2-WT (1RIB) from $E$. coli. Specific H-bonding interactions that are crucial for $\mathrm{R} 2$ reactivity are shown in purple (dotted line). The structures were generated using the crystallographic coordinates from the indicated PDB files. 


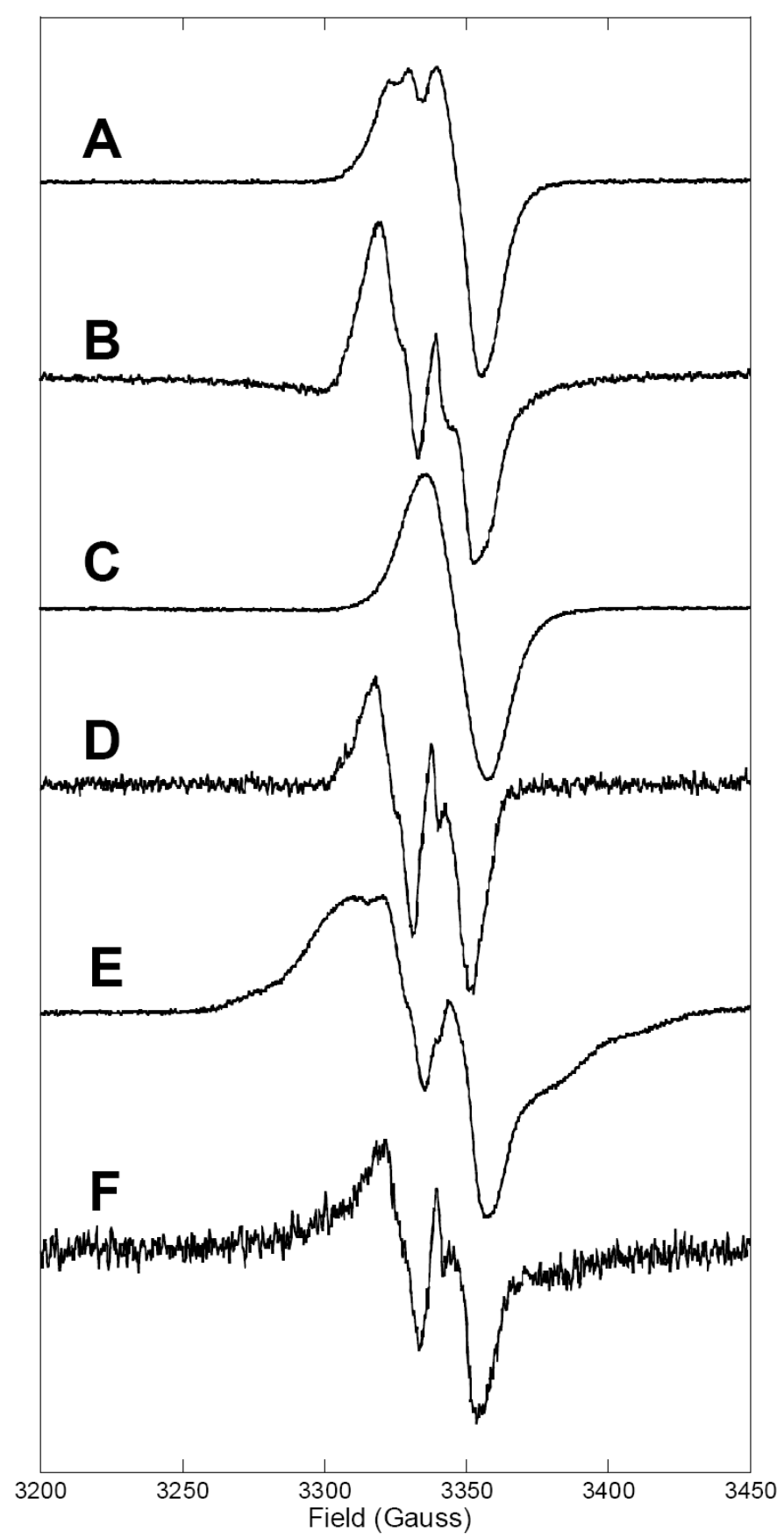

Figure 2.

RFQ-EPR spectra of (A) the intermediate $\mathrm{X}$ in $\mathrm{R} 2-\mathrm{WT}$ (relative ratio of $\mathrm{X}$ and $\mathrm{Y} 122$ 0.62:0.42), (C) in R2-Y122F/Y356F (98-100\% X), and (E) the X-Y• (79\%) diradical species, formed in the reaction of apo enzymes with $\mathrm{Fe}^{\mathrm{II}}$ and $\mathrm{O}_{2}$, in comparison with EPR spectra of decayed intermediate X in R2-WT, R2-Y122F/Y356F, and R2-W48A (B, D, and F). The EPR spectra of decayed $\mathrm{X}$ were obtained by allowing the samples of $\mathrm{X}$ to thaw at room temperature for 10 minutes prior to freezing in liquid nitrogen. The spectrometer conditions for data acquisition were: microwave frequency $9.38 \mathrm{GHz}$, temperature $3.0 \mathrm{~K}$, microwave power 10 $\mu \mathrm{W}$, modulation frequency $100 \mathrm{KHz}$, modulation amplitude $4 \mathrm{G}$, and receiver gain of $2.24 \times$ $10^{4}$. 


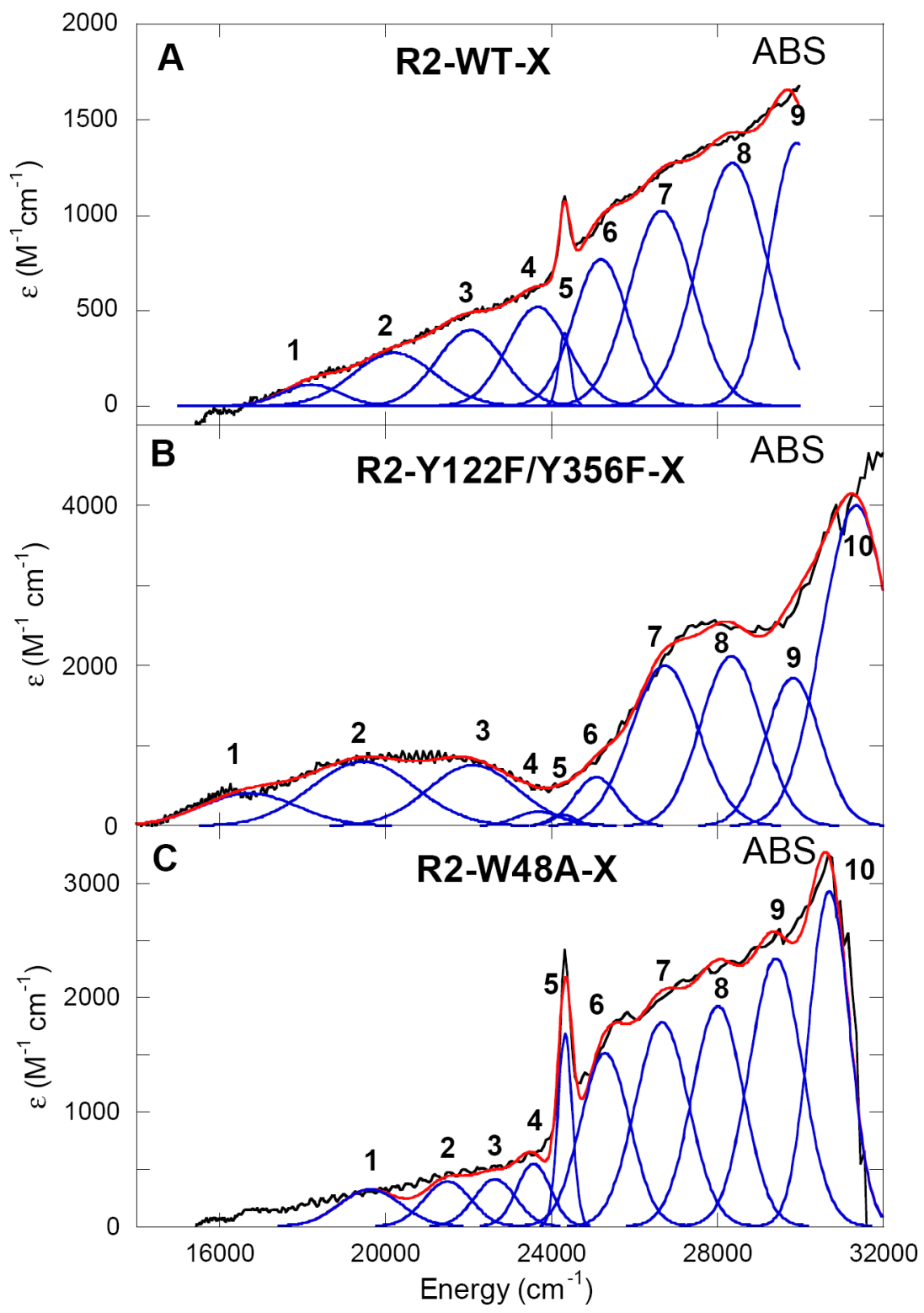

Figure 3.

Low temperature $(10 \mathrm{~K}$ ) absorption spectra of intermediate $\mathrm{X}$ in (A) R2-WT, (B) R2-Y122F/ Y356F, and (C) R2-W48A with simultaneous Gaussian fitting with their respective MCD data. 


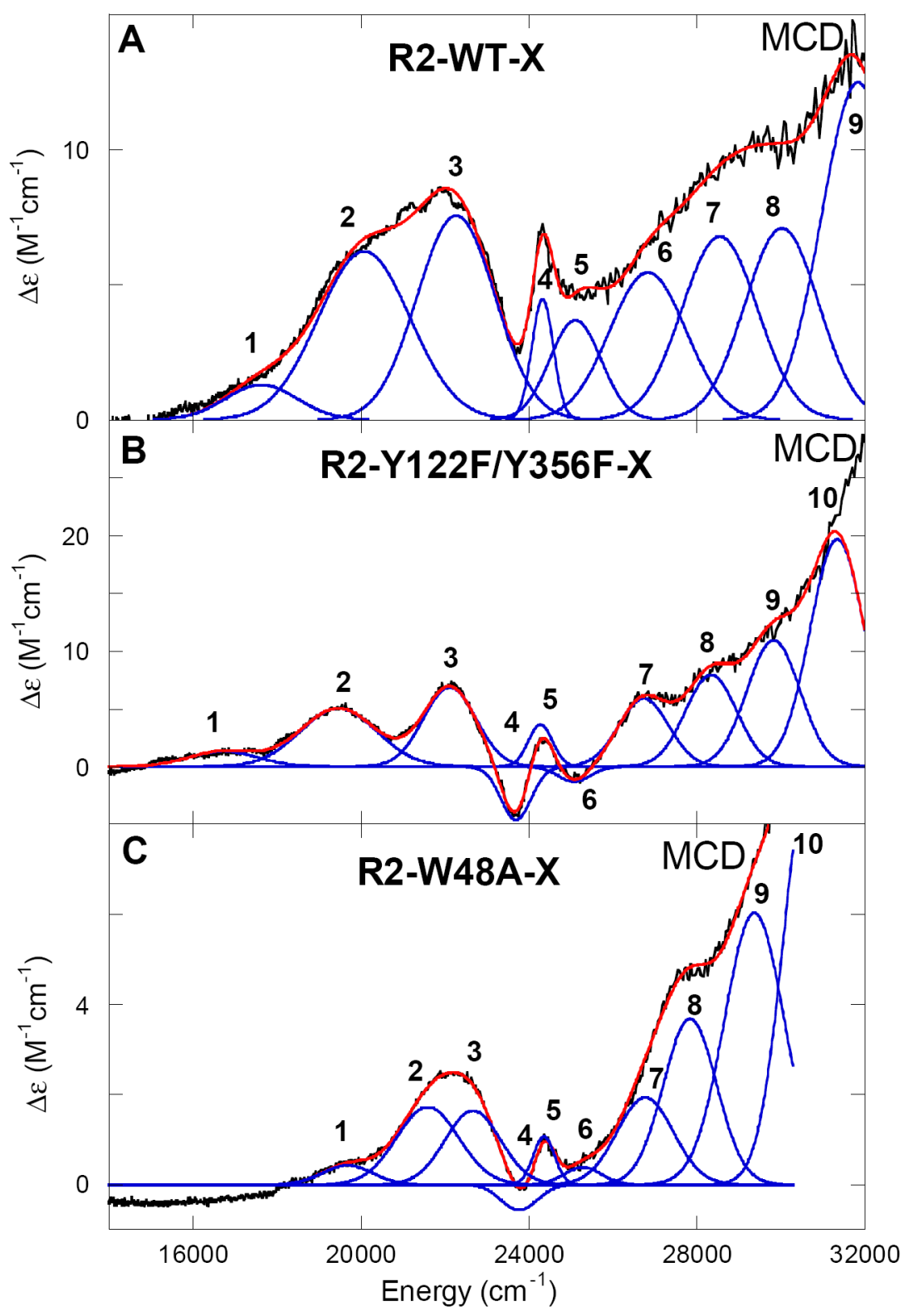

Figure 4.

Low temperature RFQ-MCD (1.8 K, 7 T) spectra of intermediate X in (A) R2-WT, (B) R2$\mathrm{Y} 122 \mathrm{~F} / \mathrm{Y} 356 \mathrm{~F}$, and (C) R2-W48A with simultaneous Gaussian fitting with their respective absorption spectra. 


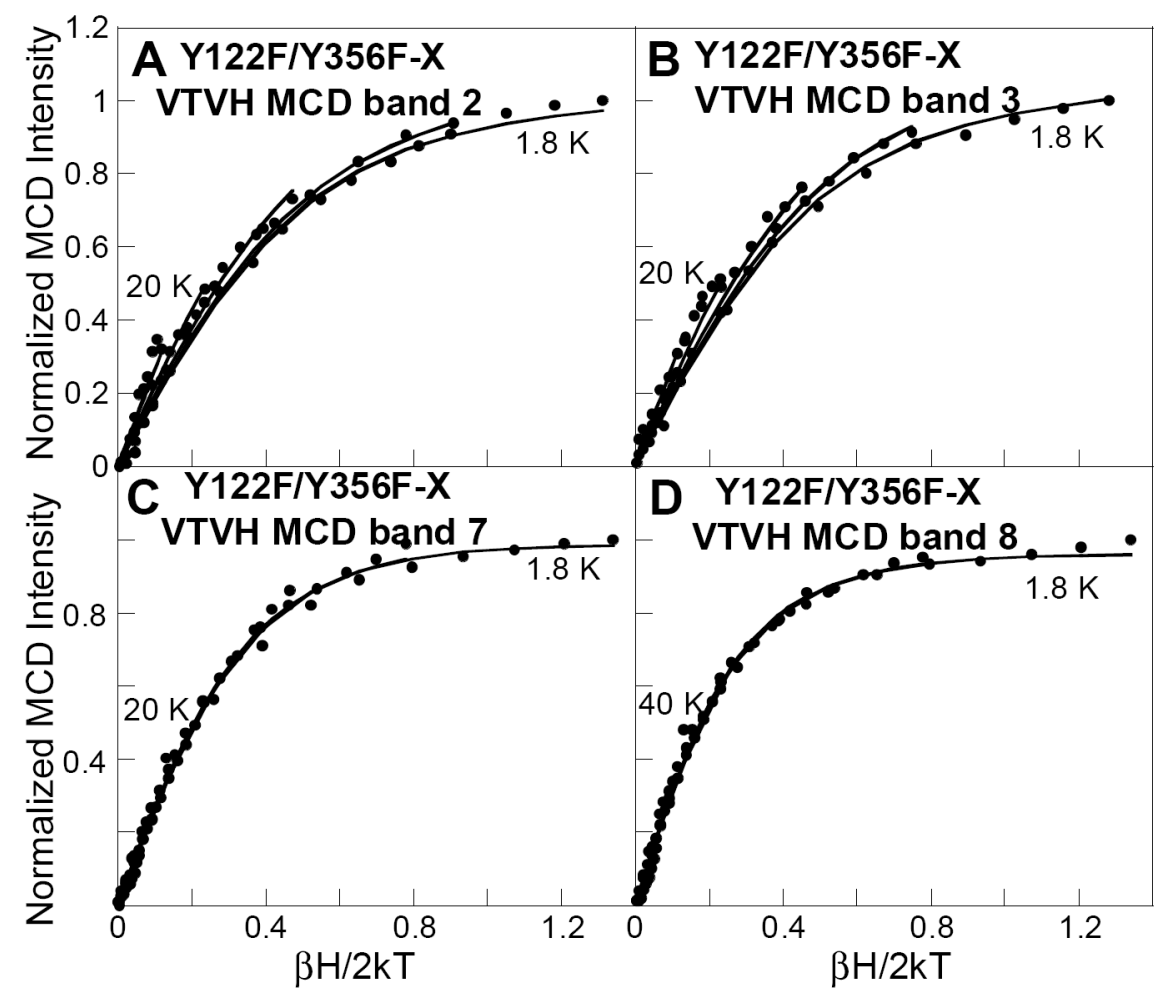

Figure 5.

VTVH MCD data of X in R2-Y122F/Y356F variant showing unnested saturation behavior within experimental standard deviation: (A) band 2 at $19230 \mathrm{~cm}^{-1}$, (B) band 3 at 22220 $\mathrm{cm}^{-1}$, (C) band 7 at $26810 \mathrm{~cm}^{-1}$, and (D) band 8 at $28740 \mathrm{~cm}^{-1}$ at $1.8,3.0,5.0,10,20 \mathrm{~K}$, and $40 \mathrm{~K}$. The magnetization data were fit with a spin Hamiltonian for a $S=1 / 2$ ground state Kramer's doublet. 60 


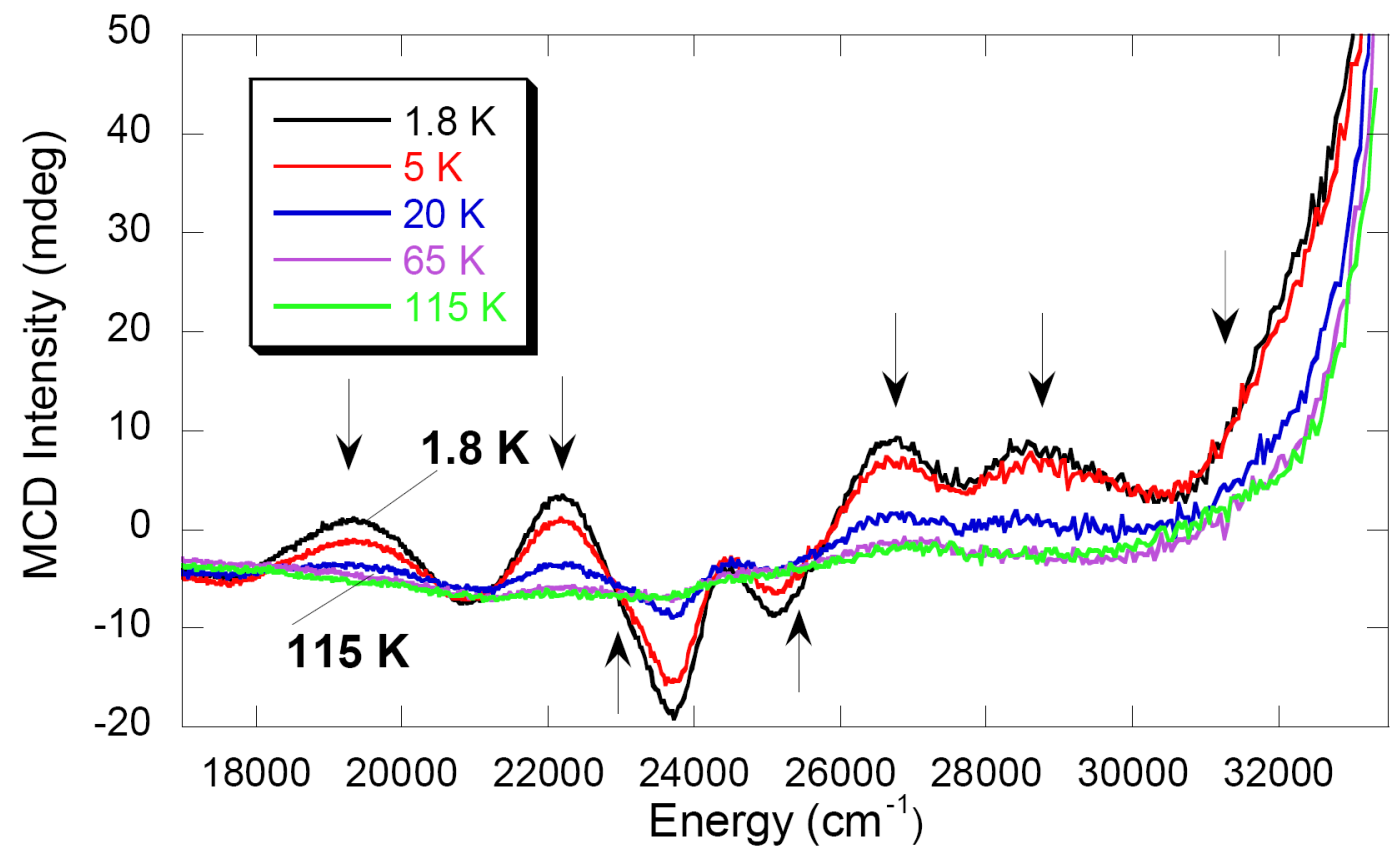

Figure 6.

Temperature dependence of MCD signal of intermediate X in R2-Y122F/Y356F. All MCD bands decrease in intensity with increase in temperature indicative of $C$-term MCD behavior. 


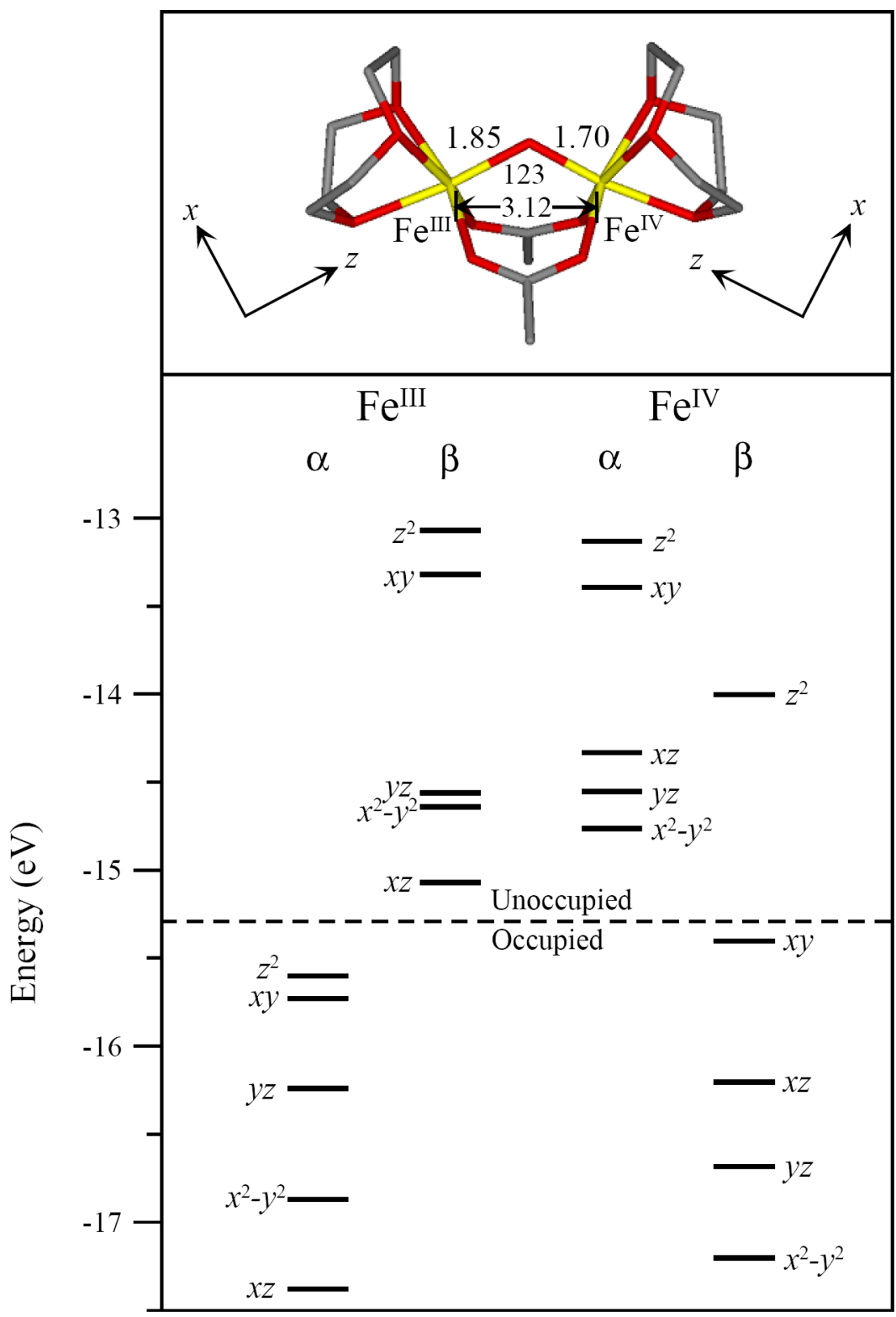

Figure 7.

Energy level diagram of the $S_{\text {tot }}=1 / 2$ unrestricted DFT geometry optimized mono- $\mu$-oxo, $\left[\mathrm{Fe}^{\mathrm{III}}(\mu-\mathrm{O}) \mathrm{Fe}^{\mathrm{IV}}\right]$ core structure. The top portion displays the mono- $\mu$-oxo structure with $\mathrm{Fe}-\mathrm{O}$ and $\mathrm{Fe}-\mathrm{Fe}$ distance and angle data. Local coordinate frames are displayed for each iron. Ligand hydrogens are omitted for clarity. 


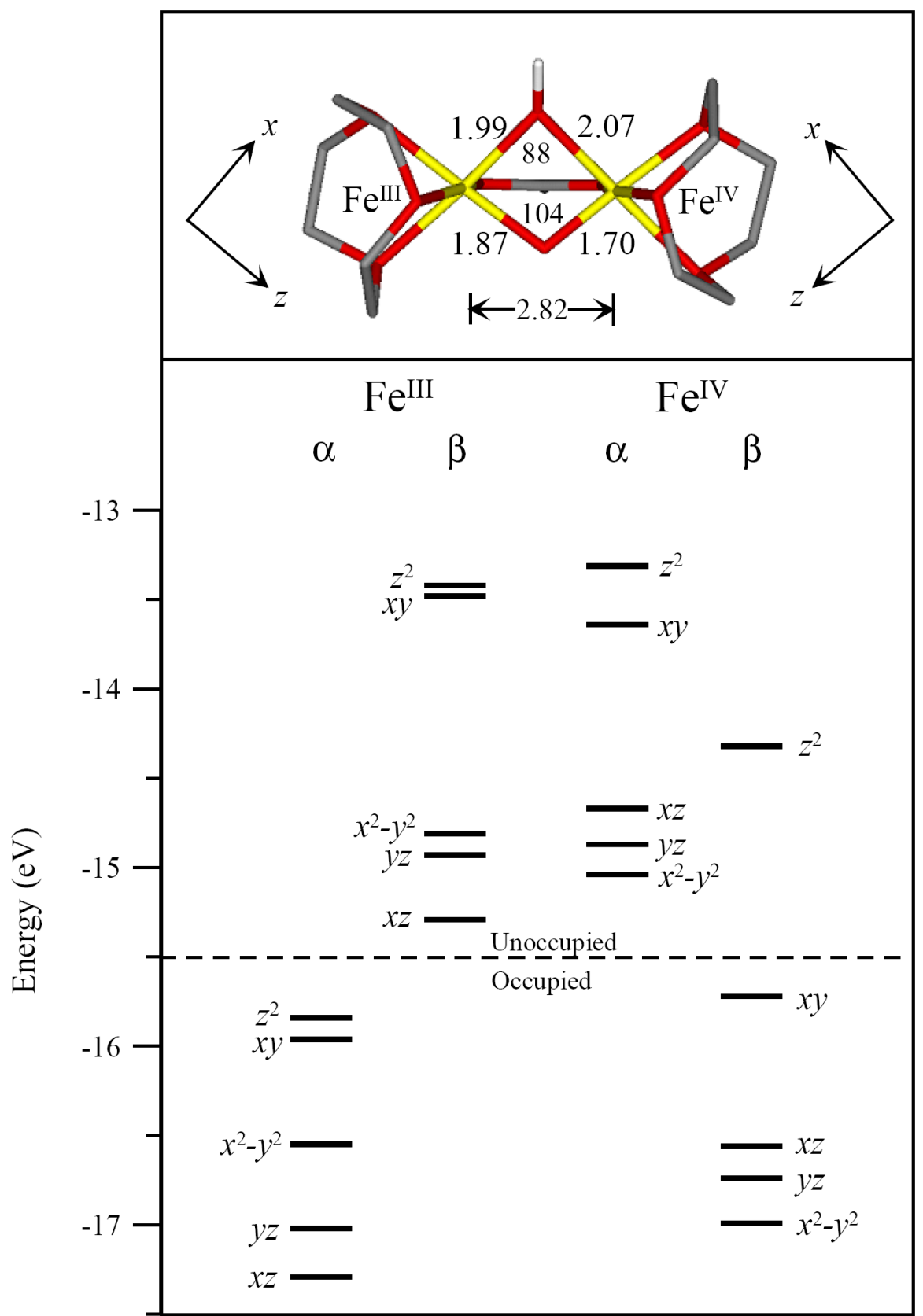

Figure 8.

Energy level diagram of the $S_{\text {tot }}=1 / 2$ unrestricted DFT geometry optimized $\mu$-oxo/ $\mu$-hydroxo, $\left[\mathrm{Fe}^{\mathrm{III}}(\mu-\mathrm{O})(\mu-\mathrm{OH}) \mathrm{Fe}^{\mathrm{IV}}\right]$ core structure. The top portion displays the $\mu$-oxo/ $\mu$-hydroxo structure with $\mathrm{Fe}-\mathrm{O}$ and $\mathrm{Fe}-\mathrm{Fe}$ distance and angle data. Local coordinate frames are displayed for each iron. Non-oxo ligand hydrogens are omitted for clarity. 


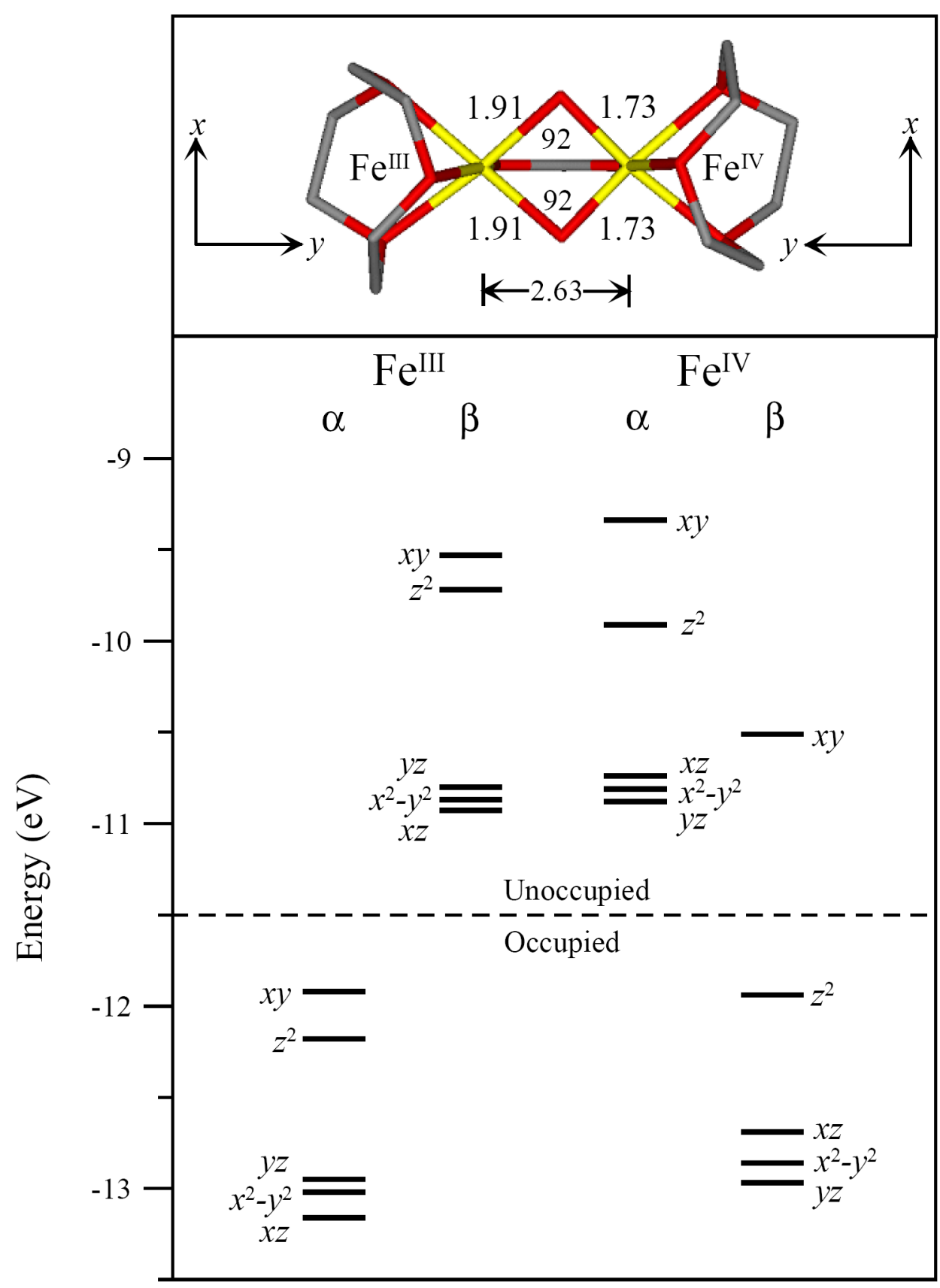

Figure 9.

Energy level diagram of the $S_{\text {tot }}=1 / 2$ unrestricted DFT geometry optimized bis- $\mu$-oxo, $\left[\mathrm{Fe}^{\mathrm{III}}(\mu-\mathrm{O})_{2} \mathrm{Fe}^{\mathrm{IV}}\right]$ core structure. The top portion displays the bis- $\mu$-oxo structure with Fe-O and $\mathrm{Fe}-\mathrm{Fe}$ distance and angle data. Local coordinate frames are displayed for each iron. Ligand hydrogens are omitted for clarity. 
(a)

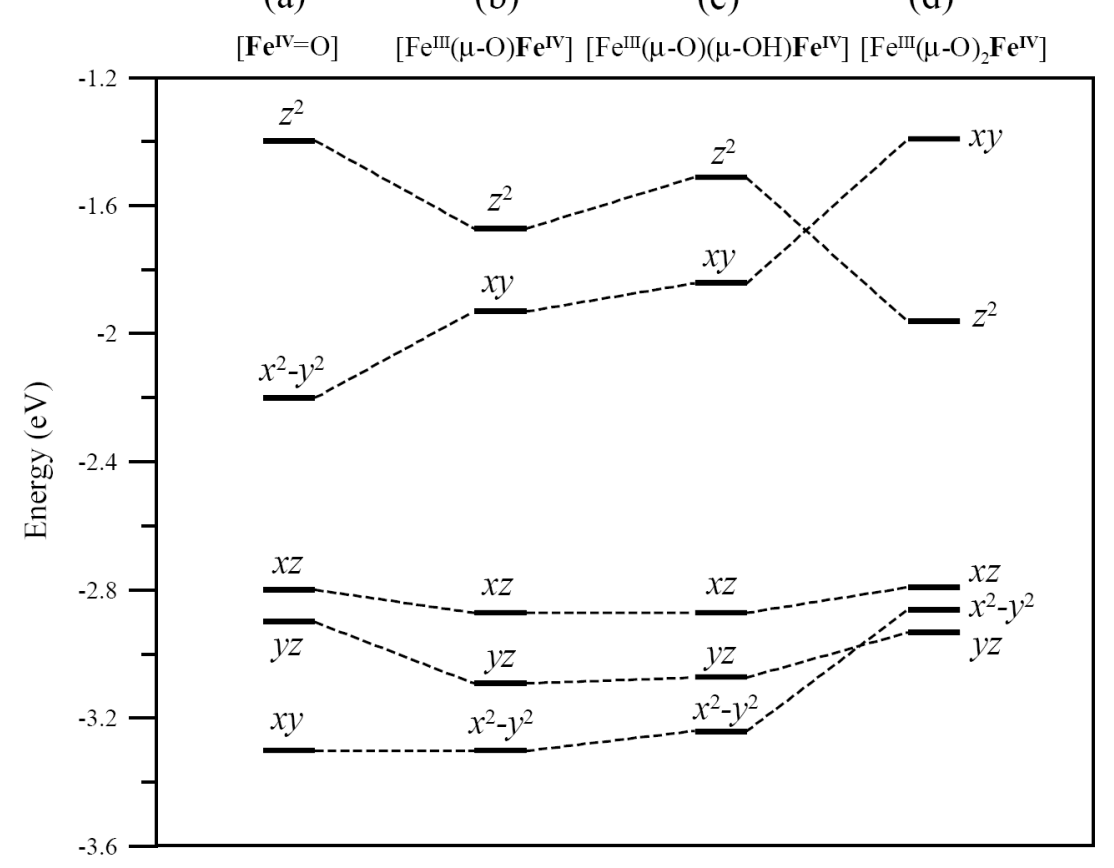

Figure 10.

Comparison of the unoccupied $\alpha \mathrm{Fe}^{\mathrm{IV}}$ d-orbital energy levels between the (a) mononuclear $\mathrm{Fe}^{\mathrm{IV}}=\mathrm{O} S=2$; (b) mono- $\mu$-oxo, $S_{\mathrm{tot}}=1 / 2$; (c) $\mu$-oxo $/ \mu$-hydroxo, $S_{\mathrm{tot}}=1 / 2$; and (d) bis- $\mu$-oxo, $S_{\text {tot }}=1 / 2$ structures. 


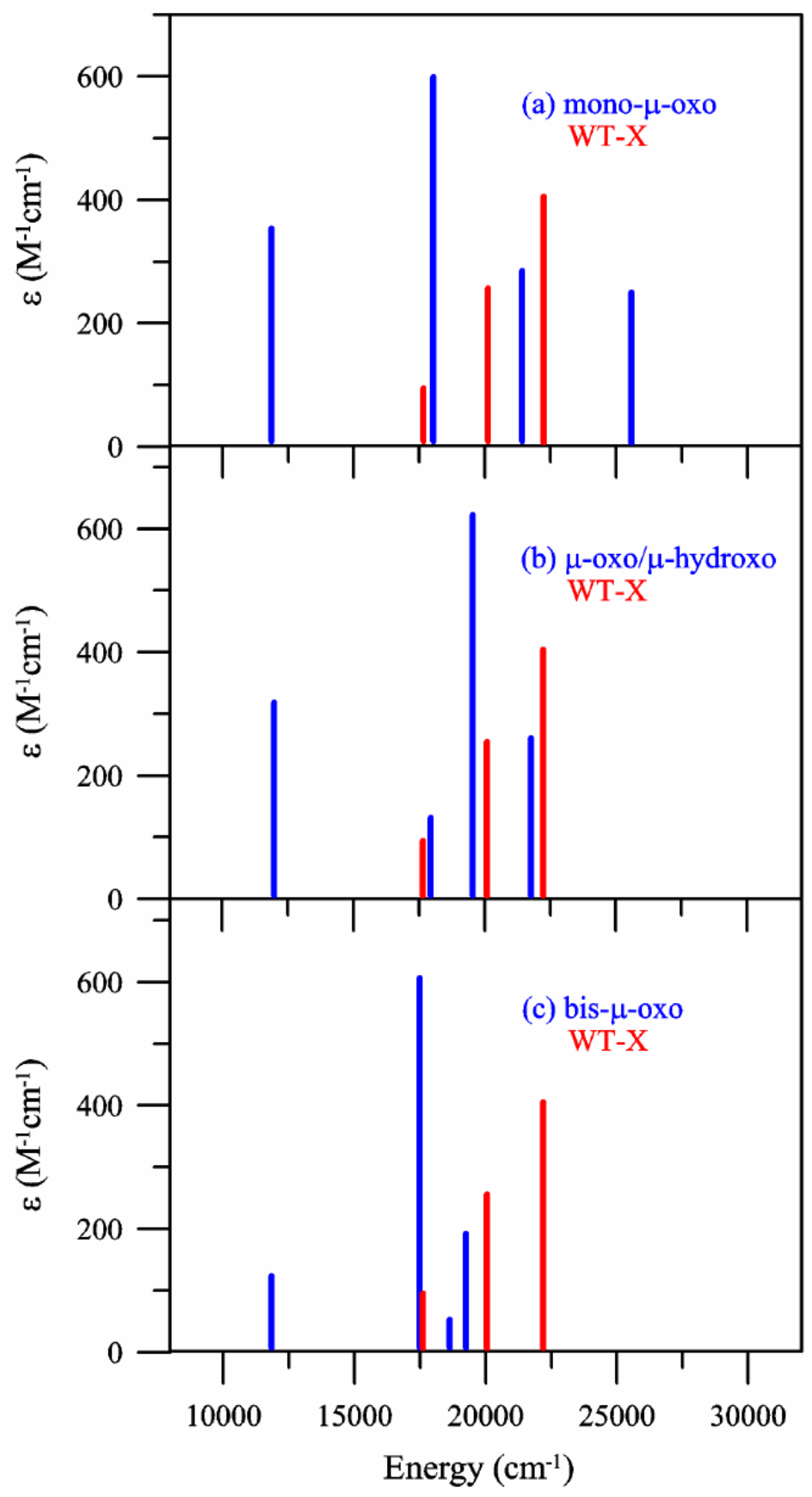

Figure 11.

$\mathrm{Fe}^{\mathrm{IV}} \mathrm{d}-\mathrm{d}$ transition comparison between the experimental WT-X data and the computational TD-DFT data of the (a) mono- $\mu$-oxo, (b) $\mu$-oxo $/ \mu$-hydroxo and (c) bis- $\mu$-oxo model structures. Each stick represents an $\mathrm{Fe}^{\mathrm{IV}}$ d-d transition. 

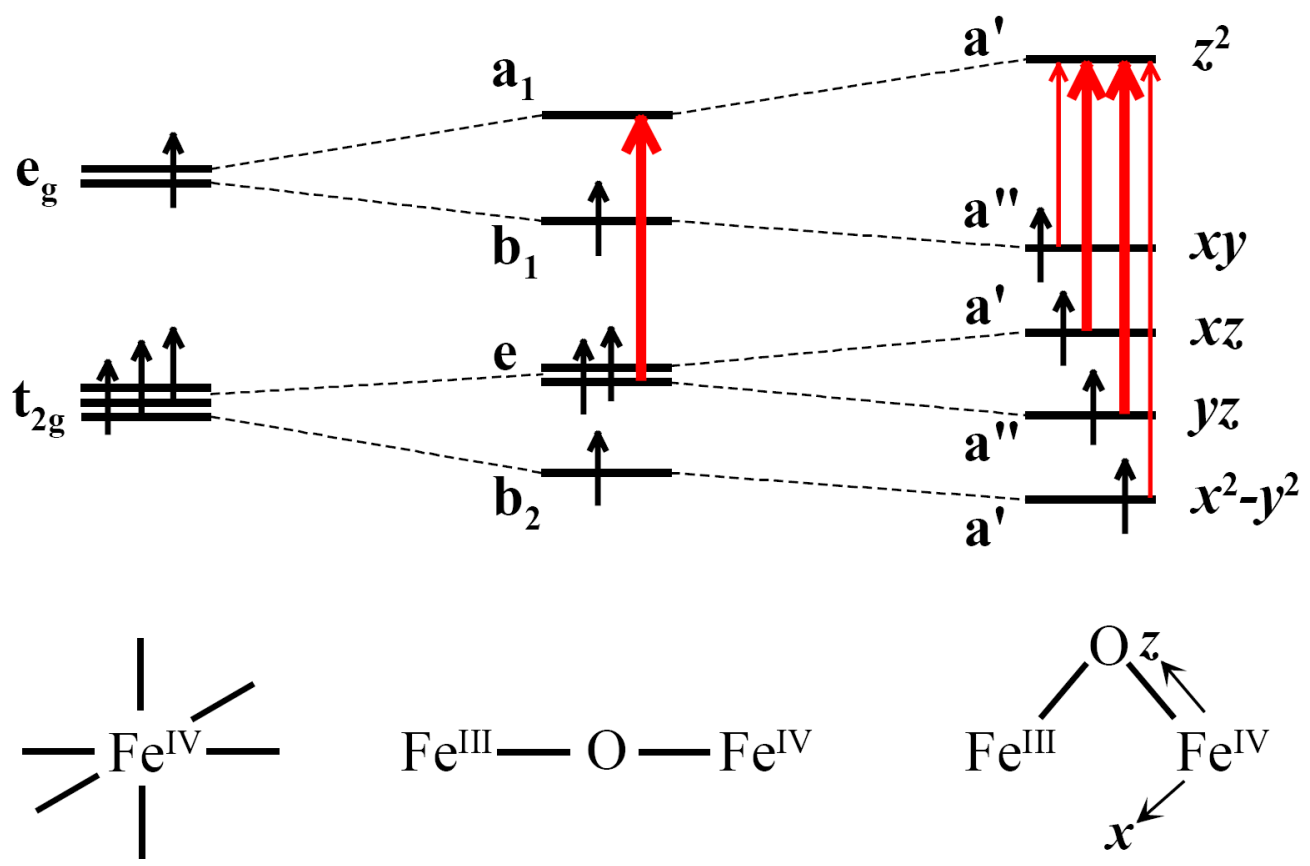

Figure 12.

Qualitative splitting of $\mathrm{Fe}^{\mathrm{IV}}$ d-orbitals mono- $\mu$-oxo and $\mu$-oxo/ $\mu$-hydroxo under dissent in symmetry. There are four spin-allowed d-d transitions. The thick red arrows represent $\mathrm{Fe}^{\mathrm{IV}} \mathrm{d}$ $\mathrm{d}$ transitions which are predicted to be more intense than the $d-d$ transitions with thin red arrows, due to the lowering of symmetry. 

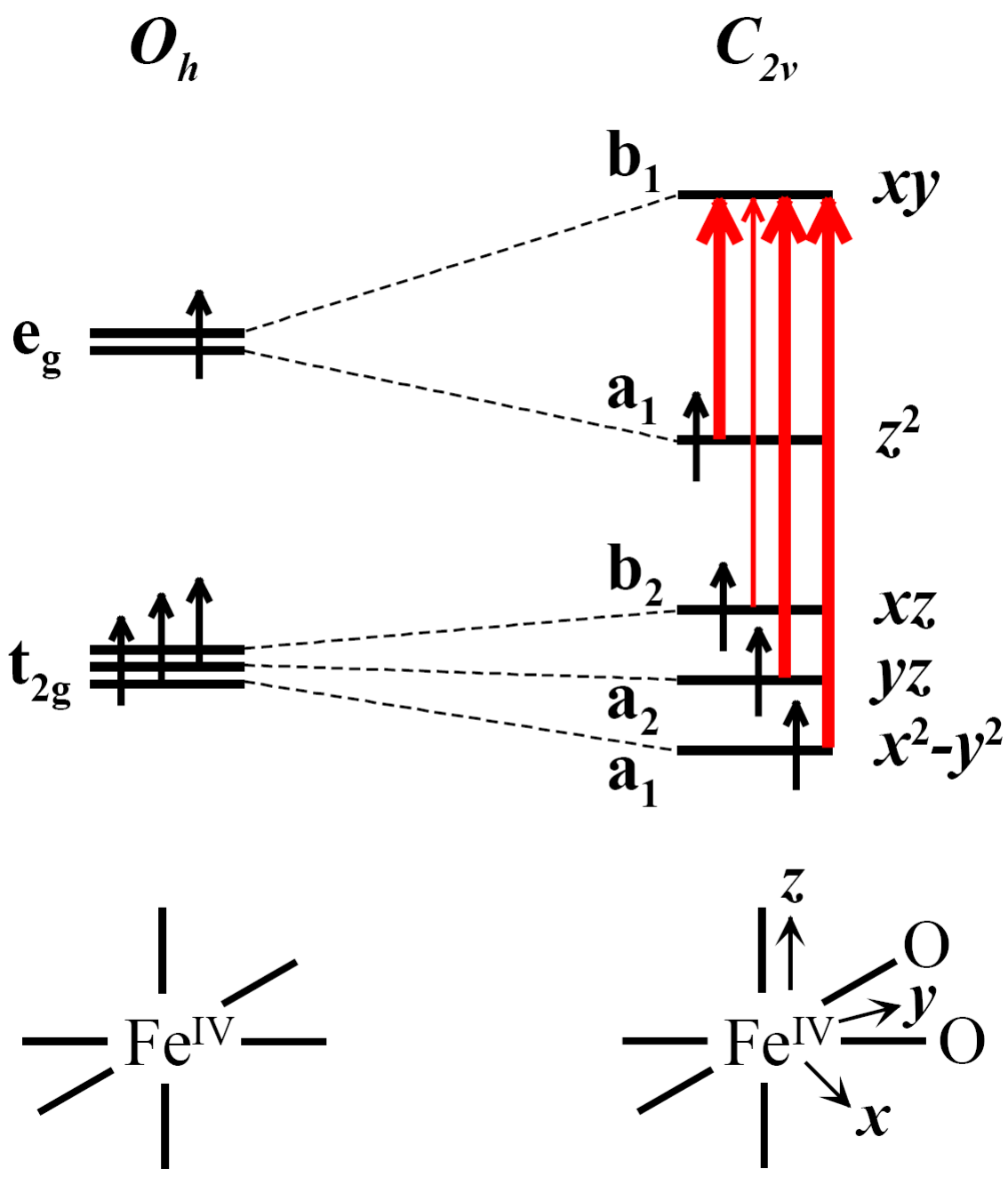

Figure 13.

Qualitative splitting of bis- $\mu$-oxo $\mathrm{Fe}^{\mathrm{IV}} \mathrm{d}$-orbitals under dissent in symmetry. There are four

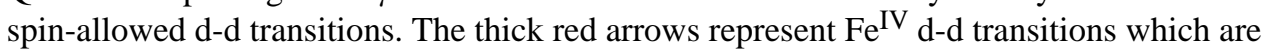
orbitally allowed in $C_{2 \mathrm{v}}$. The thin red arrow becomes allowed, due to the lowering of symmetry. 


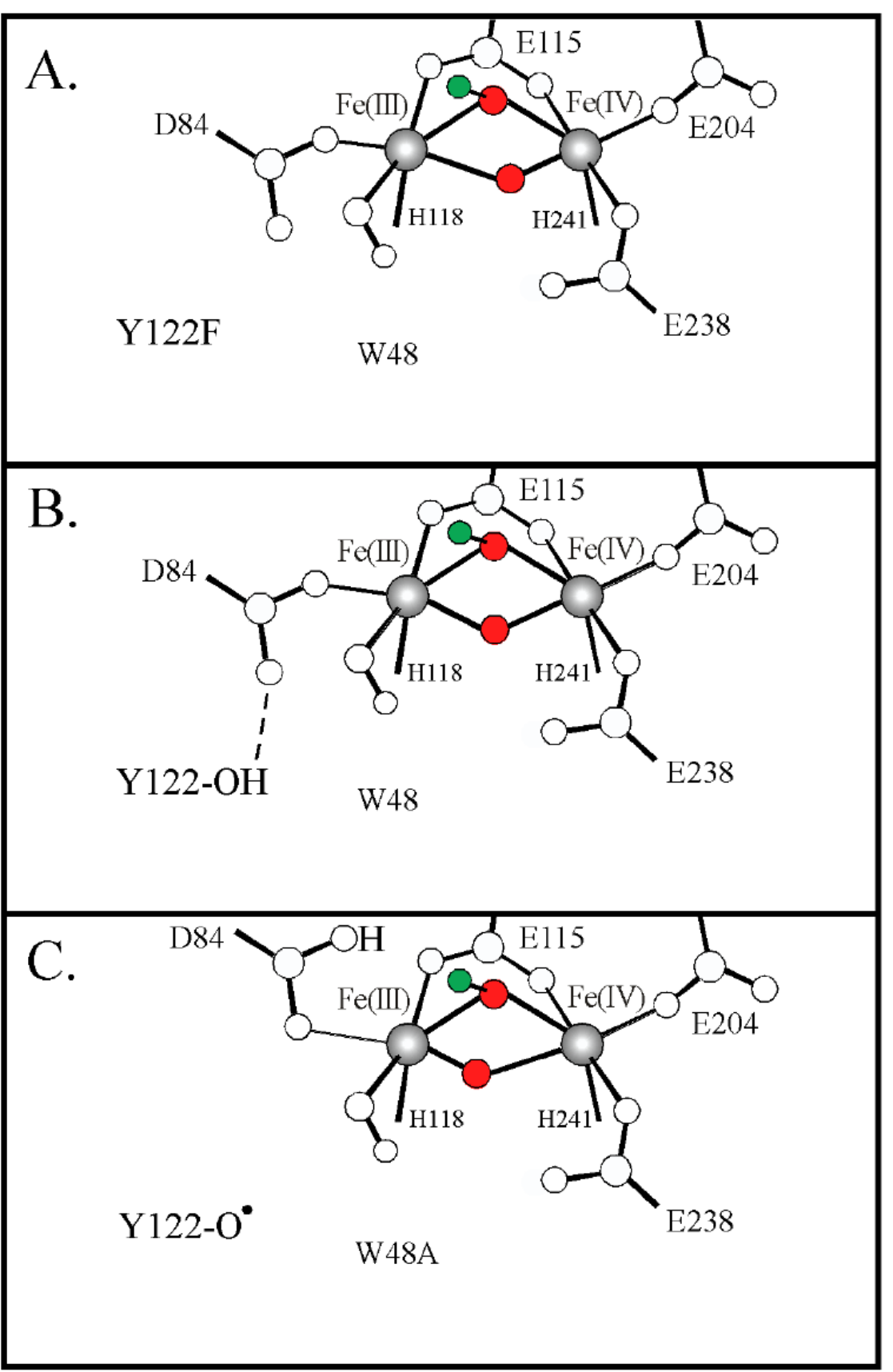

Figure 14.

Proposed structural perturbations of X in (A) Y122F/Y356F, (B) WT, and (C) W48A variants. The $\mu$-oxo/ $\mu$-hydroxo core structure of $\mathrm{X}$ is composed of oxygen atoms that derive from $\mathrm{O}_{2}$ colored red and a proton colored green. 


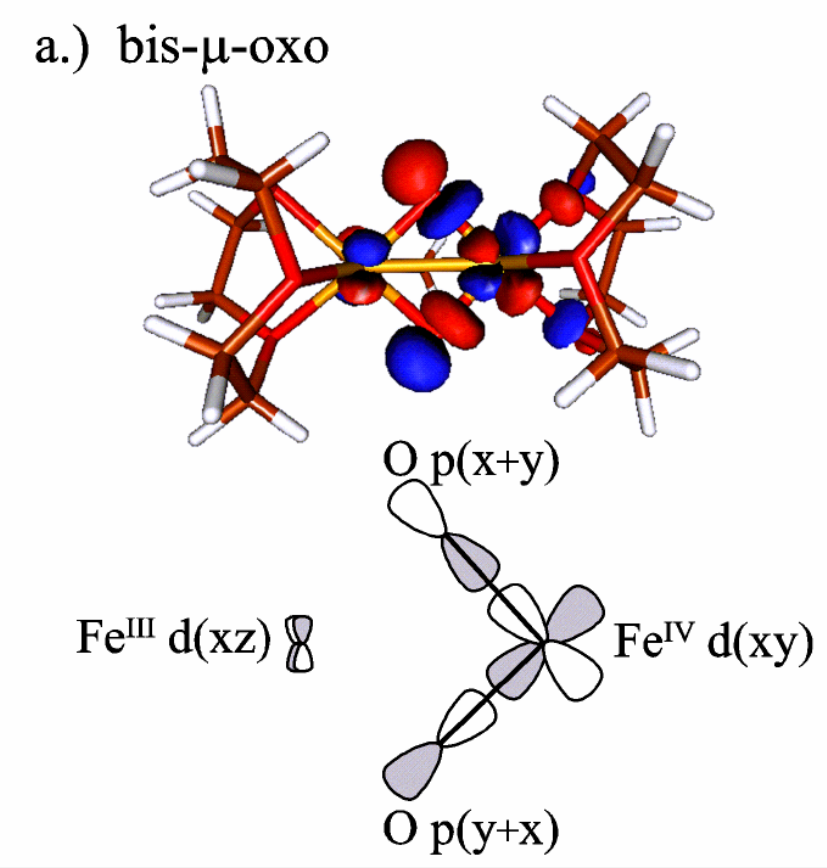

b.) $\mu$-oxo/hydroxo
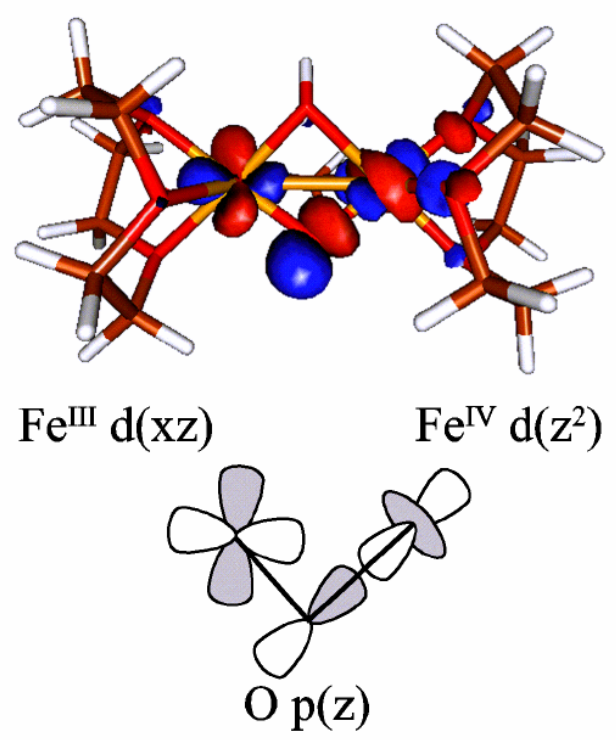

Figure 15.

Electron transfer pathways for the LUMO ( $\beta$-124) of both the (A) bis- $\mu$-oxo and (B) $\mu$-oxo $/ \mu$ hydroxo structures. The bis- $\mu$-oxo structure does not show a good ET pathway, whereas the $\mu$-oxo/ $\mu$-hydroxo structure displays a good $\pi / \sigma$ superexchange ET pathway. 


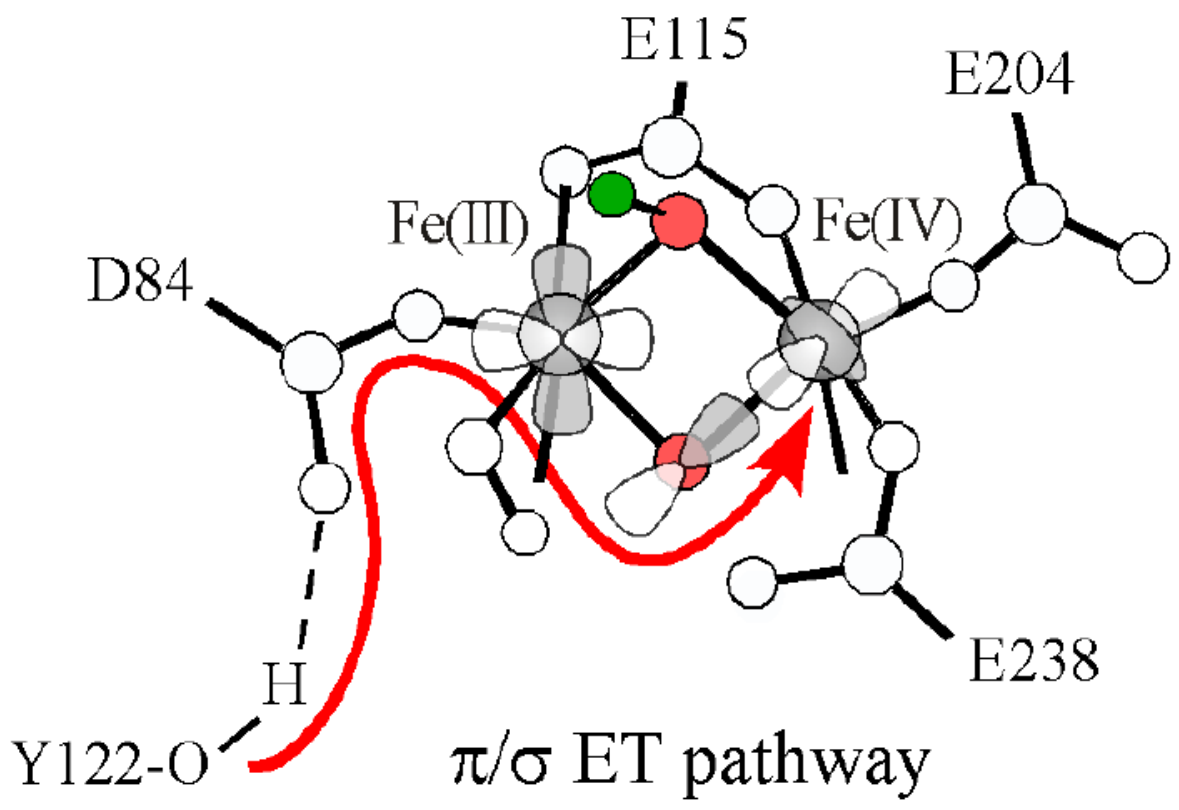

Figure 16.

Proposed ET pathway from Y122 to the remote $\mathrm{Fe}^{\mathrm{IV}}$ through the $\pi / \sigma$ superexchange pathway of the $\mu$-oxo bridge. 


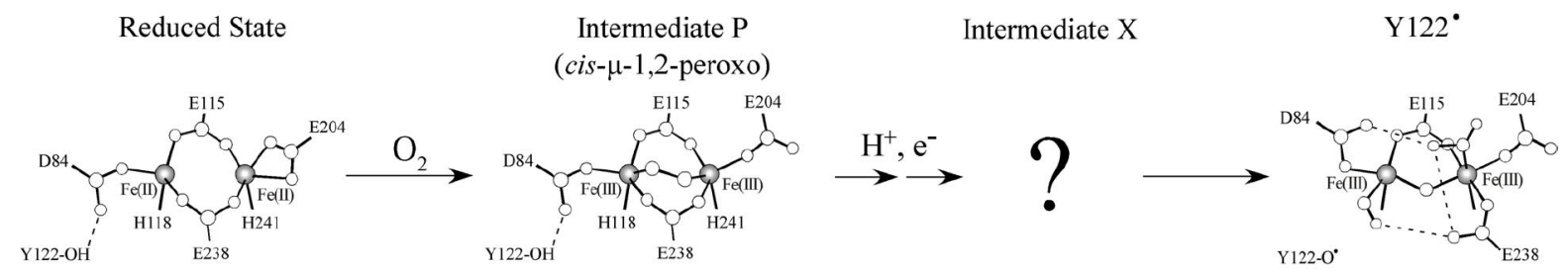

Scheme 1.

Reaction mechanism of $\mathrm{O}_{2}$ activation and tyrosyl radical (Y122•) generation from the E. coli class I RNR R2 binuclear iron site. 


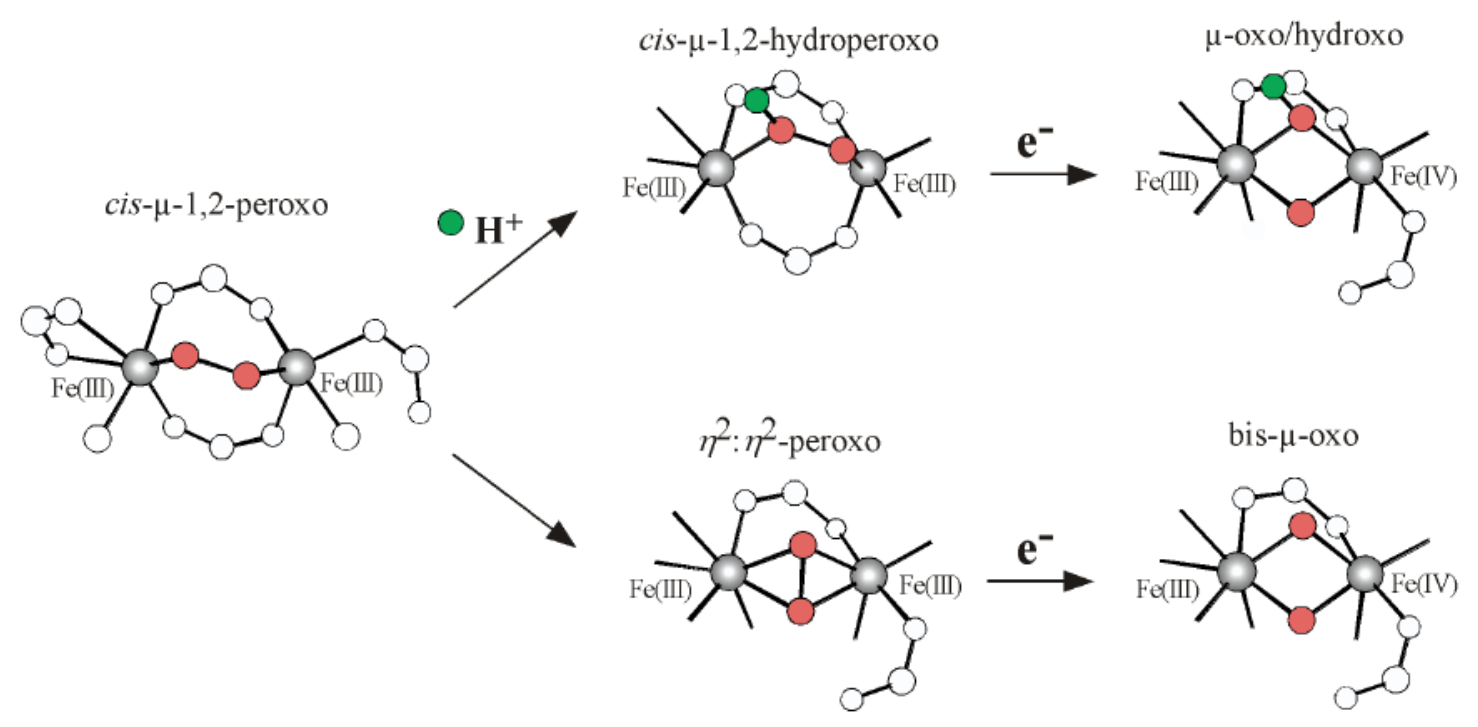

Scheme 2.

Possible $\mathrm{O}_{2}$ cleavage pathways to generate the high-valent intermediate $\mathrm{X}$. (Top) protontriggered and (Bottom) non proton-triggered. Both pathways derive one electron from an exogenous source and the other electron from the remote Fe. 


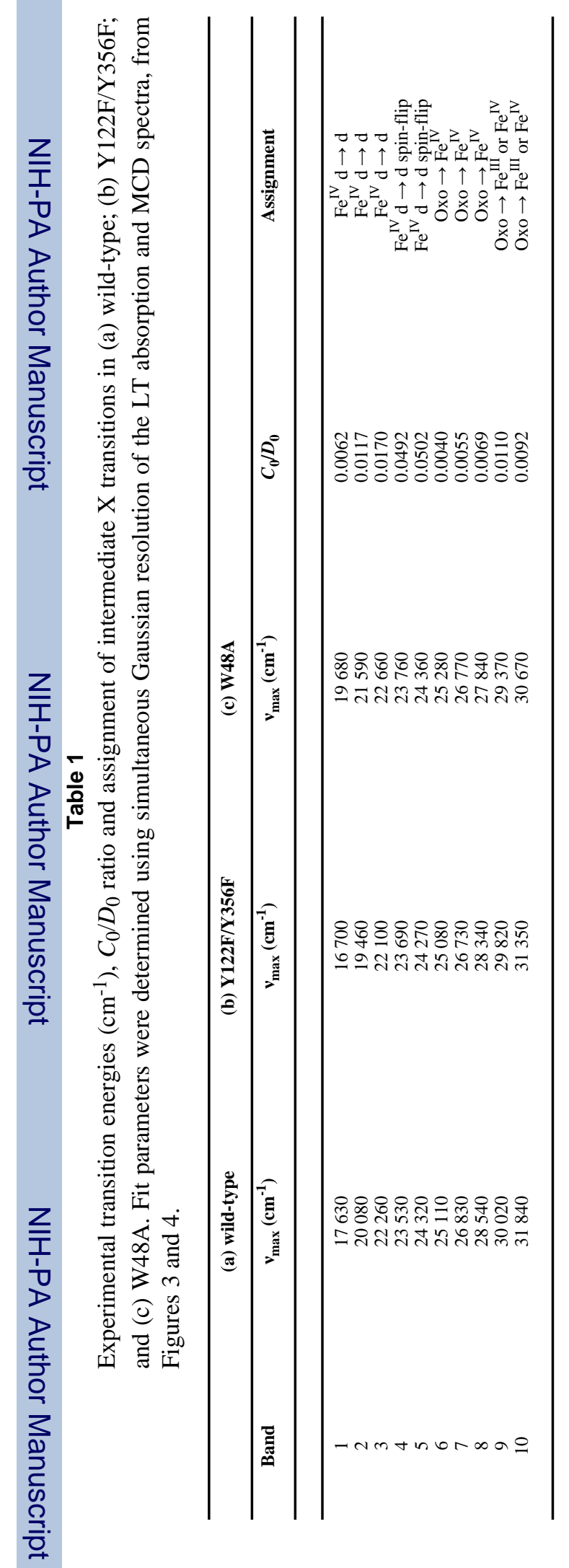


Mití et al.

Page 40

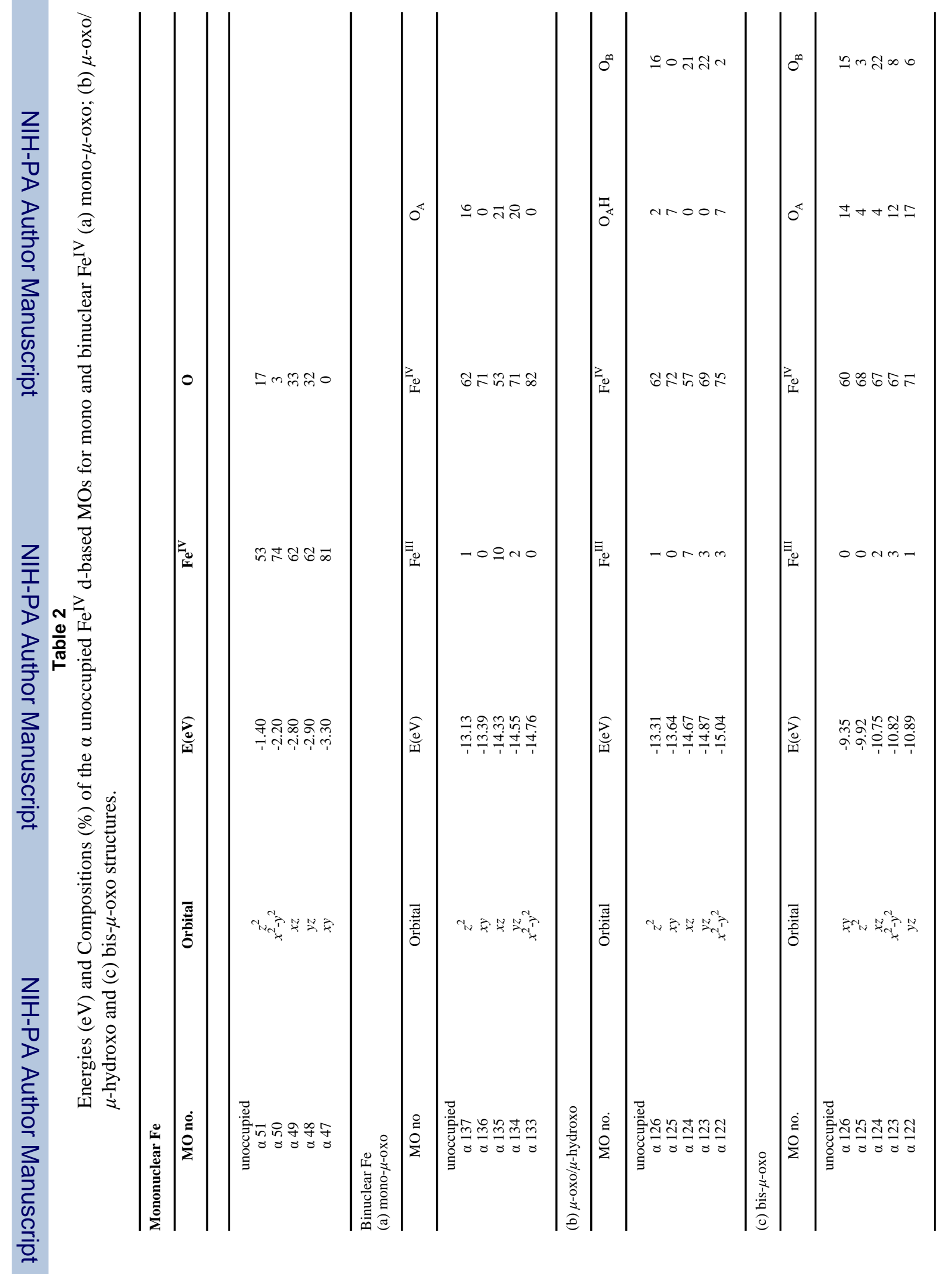

J Am Chem Soc. Author manuscript; available in PMC 2008 October 9. 
Mití et al.

Page 41

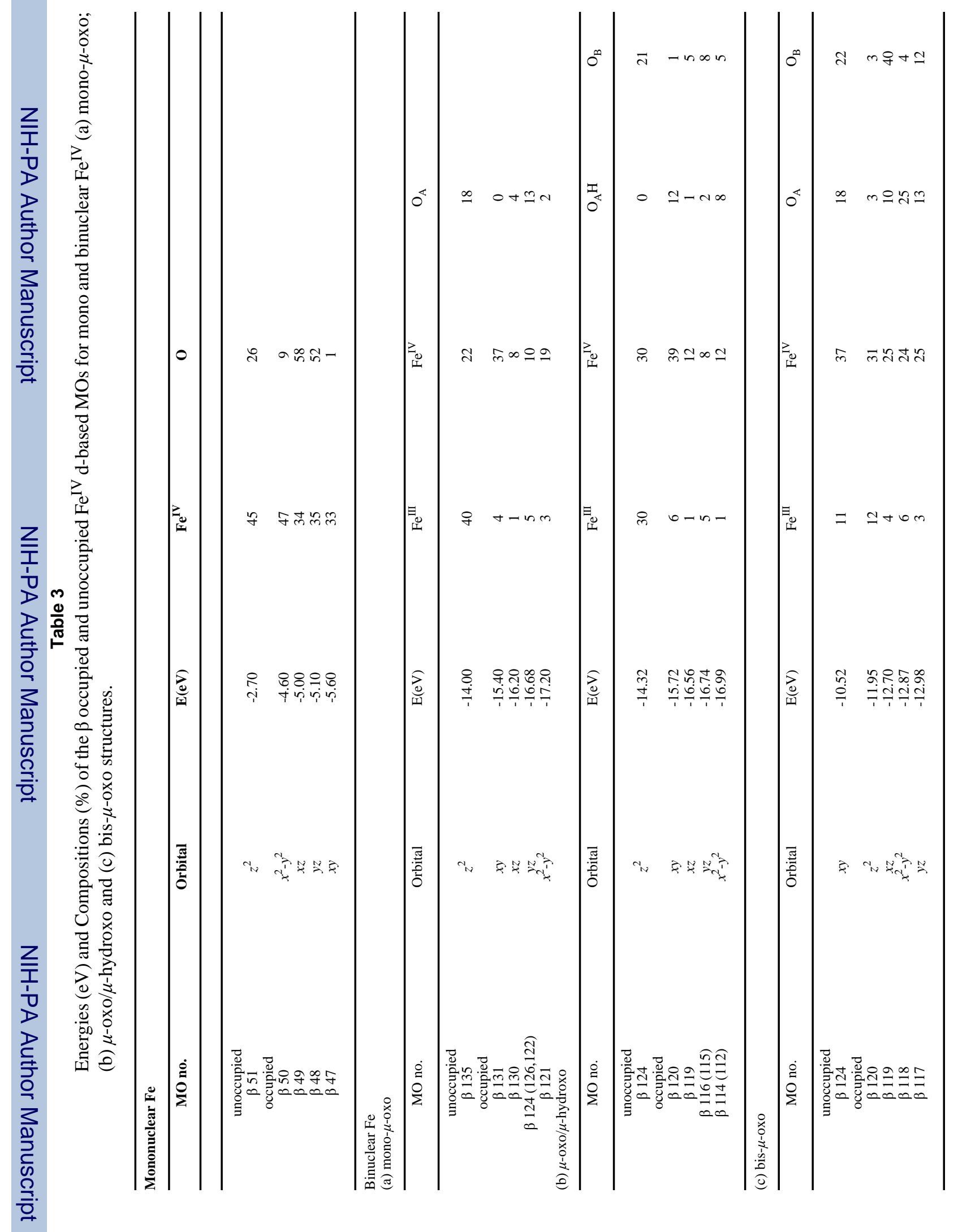

$J$ Am Chem Soc. Author manuscript; available in PMC 2008 October 9. 
Table 4

TD-DFT calculated transition energies $v_{\text {calc }}\left(\mathrm{cm}^{-1}\right)$, oscillator strength $(f)$, composition $(\%)$ and dominant one-electron excitation of relevant $\mathrm{Fe}^{\mathrm{IV}} \mathrm{d}$-d transitions in (a) mono- $\mu$-oxo; (b) $\mu$-oxo/ $\mu$-hydroxo and (c) bis- $\mu$-oxo structures.

(a) mono- $\mu$-oxo

\begin{tabular}{|c|c|c|c|}
\hline$v_{\text {calc }}\left(\mathrm{cm}^{-1}\right)$ & $f$ & $\%$ & $\mathrm{Fe}^{\mathrm{IV}}$ one-electron excitation \\
\hline $\begin{array}{l}11871 \\
18021 \\
21404 \\
25562\end{array}$ & $\begin{array}{l}0.0010 \\
0.0017 \\
0.0008 \\
0.0007\end{array}$ & $\begin{array}{l}62 \\
41 \\
69 \\
55\end{array}$ & $\begin{array}{c}\mathrm{xy}(\beta 131) \rightarrow \mathrm{z}^{2}(\beta 135) \\
\mathrm{xz}(\beta 130) \rightarrow \mathrm{z}^{2}(\beta 135) \\
\mathrm{yz}(\beta 124) \rightarrow \mathrm{z}^{2}(\beta 135) \\
\mathrm{x}^{2}-\mathrm{y}^{2}(\beta 121) \rightarrow \mathrm{z}^{2}(\beta 135)\end{array}$ \\
\hline \multicolumn{4}{|l|}{ (b) $\mu$-oxo $/ \mu$-hydroxo } \\
\hline$v_{\text {calc }}\left(\mathrm{cm}^{-1}\right)$ & $f$ & $\%$ & $\mathrm{Fe}^{\mathrm{IV}}$ one-electron excitation \\
\hline $\begin{array}{l}11946 \\
17905 \\
19512 \\
21730\end{array}$ & $\begin{array}{l}0.0027 \\
0.0011 \\
0.0053 \\
0.0022\end{array}$ & $\begin{array}{l}64 \\
46 \\
55 \\
18\end{array}$ & $\begin{array}{c}\mathrm{xy}(\beta 120) \rightarrow \mathrm{z}^{2}(\beta 124) \\
\mathrm{xz}(\beta 119) \rightarrow \mathrm{z}^{2}(\beta 124) \\
\mathrm{yz}(\beta 116) \rightarrow \mathrm{z}^{2}(\beta 124) \\
\mathrm{x}^{2}-\mathrm{y}^{2}(\beta 114) \rightarrow \mathrm{z}^{2}\left(\begin{array}{ll}\beta & 124)\end{array}\right)\end{array}$ \\
\hline \multicolumn{4}{|l|}{ (c) bis- $\mu$-oxo } \\
\hline$v_{\text {calc }}\left(\mathrm{cm}^{-1}\right)$ & $f$ & $\%$ & $\mathrm{Fe}^{\mathrm{IV}}$ one-electron excitation \\
\hline $\begin{array}{l}11858 \\
17507 \\
18660 \\
19283\end{array}$ & $\begin{array}{l}0.0003 \\
0.0017 \\
0.0001 \\
0.0005\end{array}$ & $\begin{array}{l}83 \\
42 \\
83 \\
76\end{array}$ & $\begin{aligned} \mathrm{z}^{2}(\beta 120) & \rightarrow \mathrm{xy}(\beta 124) \\
\mathrm{xz}(\beta 119) & \rightarrow \mathrm{xy}(\beta 124) \\
\mathrm{yz}(\beta 118) & \rightarrow \mathrm{xy}(\beta 124) \\
\mathrm{x}^{2}-\mathrm{y}^{2}(\beta 117) & \rightarrow \mathrm{xy}(\beta 124)\end{aligned}$ \\
\hline
\end{tabular}




\section{Table 5}

Calculated Slater and $\triangle$ SCF transition energies $v_{\text {calc }}\left(\mathrm{cm}^{-1}\right)$ and designated Fe ${ }^{\mathrm{IV}}$ d-d transition in (a) mono- $\mu$-oxo; (b) $\mu$-oxo/ $\mu$-hydroxo and (c) bis- $\mu$-oxo structures.

\begin{tabular}{|c|c|c|}
\hline \multicolumn{3}{|l|}{ (a) mono- $\mu$-oxo } \\
\hline Slater, $v_{\text {calc }}\left(\mathrm{cm}^{-1}\right)$ & $\Delta \mathrm{SCF}, \mathrm{v}_{\text {calc }}\left(\mathrm{cm}^{-1}\right)$ & $\mathrm{Fe}^{\mathrm{IV}}$ d-d excitation \\
\hline $\begin{array}{l}13187 \\
19664 \\
21349 \\
24479\end{array}$ & $\begin{array}{c}12918 \\
19222 \\
21053 \\
\text { unconverged }\end{array}$ & $\begin{array}{c}x y(\beta 131) \rightarrow z^{2}(\beta 135) \\
x z(\beta 130) \rightarrow z^{2}(\beta 135) \\
y z(\beta 126) \rightarrow z^{2}(\beta 135) \\
x^{2}-y^{2}(\beta 125) \rightarrow z^{2}(\beta 135)\end{array}$ \\
\hline \multicolumn{3}{|l|}{ (b) $\mu$-oxo $/ \mu$-hydroxo } \\
\hline Slater, $v_{\text {calc }}\left(\mathrm{cm}^{-1}\right)$ & $\Delta \mathrm{SCF}, v_{\text {calc }}\left(\mathrm{cm}^{-1}\right)$ & $\mathrm{Fe}^{\mathrm{IV}}$ d-d excitation \\
\hline $\begin{array}{l}12550 \\
18946 \\
20253 \\
22696\end{array}$ & $\begin{array}{c}12226 \\
18457 \\
19983 \\
\text { unconverged }\end{array}$ & 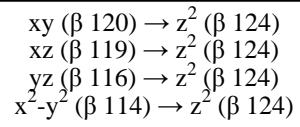 \\
\hline \multicolumn{3}{|l|}{ (c) bis- $\mu$-oxo } \\
\hline Slater, $v_{\text {calc }}\left(\mathrm{cm}^{-1}\right)$ & $\Delta \mathrm{SCF}, v_{\text {calc }}\left(\mathrm{cm}^{-1}\right)$ & $\mathrm{Fe}^{\mathrm{IV}}$ d-d excitation \\
\hline $\begin{array}{l}13437 \\
18381 \\
19970 \\
20333\end{array}$ & $\begin{array}{c}13350 \\
18469 \\
\text { unconverged } \\
\text { unconverged }\end{array}$ & $\begin{array}{c}\mathrm{z}^{2}(\beta 120) \rightarrow \mathrm{xy}(\beta 124) \\
\mathrm{xz}(\beta 119) \rightarrow \mathrm{xy}(\beta 124) \\
\mathrm{yz}(\beta 118) \rightarrow \mathrm{xy}(\beta 124) \\
\mathrm{x}^{2}-\mathrm{y}^{2}(\beta 117) \rightarrow \mathrm{xy}(\beta 124)\end{array}$ \\
\hline
\end{tabular}

